\title{
Reanalysis of Heintzichthys gouldii (Newberry), an aspinothoracid arthrodire (Placodermi) from the Famennian of northern Ohio, with a review of brachythoracid systematics
}

\author{
ROBERT K. CARR \\ Museum of Paleontology, The University of Michigan, Ann Arbor, Michigan 48109, \\ U.S.A.
}

Received October 1990, accepled for publication May 1991

Heintzichthys gouldii is redescribed based on new material from the Interstate 71 Paleontological Salvage Project (Cleveland Museum of Natural History, 1966-67). Phylogenetic analysis of brachythoracid arthrodires clearly shows the monophyly of Camuropiscidae and the aspinothoracid arthrodires. Heintzichthys gouldii and Gorgonichthys clarki are removed from Dinichthyidae and placed within aspinothoracid arthrodires. The remaining members in the family Dinichthyidac are united solely by plesiomorphic characters. A number of putative synapomorphies for the eubrachythoracid arthrodires are questioned; however, the validity of this taxon is supported by three synapomorphies.

KEY WORDS:-Devonian - Arthrodira - brachythoracid - systematics.

\section{GONTENTS}

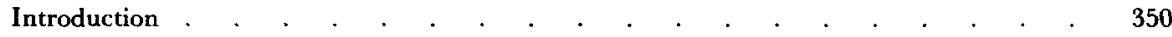

Materials . . . . . . . . . . . . . . . . . . . . 352

Description . . . . . . . . . . . . . . . . . . . . . . . . . 353

Heintzichthys gouldii (Newberry). . . . . . . . . . . . . . . . . . . . 353

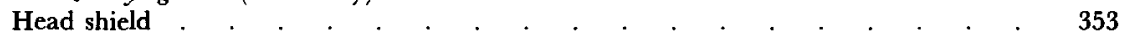

Cheek plates . . . . . . . . . . . . . . . . . . . . . . . . . . . 357

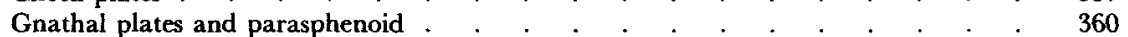

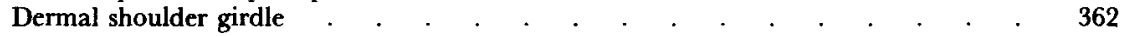

Pectoral and pelvic fins, axial skeleton and neurocranium . . . . . . . . . 367

A systematic review of brachythoracid arthrodires . . . . . . . . . . . . . . . . 371

Introduction . . . . . . . . . . . . . . . . . 371

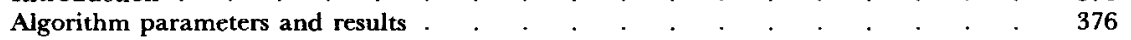

Brachythoracid arthrodires . . . . . . . . . . . . . . . . . . . . 378

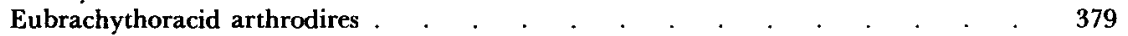

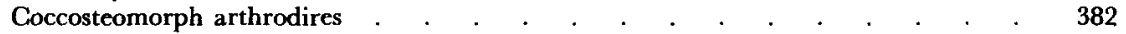

Pachyosteomorph arthrodires . . . . . . . . . . . . . . . . . 383

Family Dinichthyidac . . . . . . . . . . . . . . . . 383

Aspinothoracid arthrodires . . . . . . . . . . . . . . . 383

Selenosteid arthrodires . . . . . . . . . . . . . . . . . . . . . 384

Conclusion

Acknowledgements

References

Abbreviations used in text and figures

Appendix . 


\section{INTRODUGTION}

Arthrodires are the best known subgroup of placoderms, representing over $72 \%$ of known placoderm taxa (Denison, 1978). Dating from the Gedinnian to the Famennian (395-345 my BP) arthrodires are important for understanding early gnathostome evolution (see Table 1 for range of arthrodires in current study). Within the arthrodires, Miles (1969) noted an apparent increase in generic diversification for the Dolichothoraci and Brachythoraci. A species level analysis for Arthrodira confirms the increase for the Brachythoraci in the Middle and Late Devonian. The aspinothoracid arthrodires include most of the new taxa. Study of evolutionary trends associated with changes in species diversity requires a sound phylogenetic basis. The systematics of the Brachythoraci has been uncertain, with the fossil material from Gogo Station, Australia, having added a wealth of new information. It is important to evaluate this new information and to reanalyse North American forms that have been known since the latter part of the nineteenth century. As a first step in this effort, Heintzichthys gouldii (Newberry) is redescribed and the systematic relationships of brachythoracid arthrodires are reviewed.

The genus Heintzichthys Whitley (1933) is a subgroup within the eubrachythoracid arthrodires referred by Obruchev (1964) and Denison (1978) to the family Dinichthyidae. The type species Heintzichthys gouldii was first named by Newberry (1885) as Dinichthys gouldii, based on a disarticulated, but nearly complete specimen (AMNH 160, holotype). Synonyms also include Stenognathus gouldii Newberry (1897), Dinichthys corrugatus Newberry (1889) and Dinichthys gracilis Claypole (1893). Later, Hussakof (1911) described another nearly

TABLE 1. Stratigraphic range for arthrodiran taxa in current study. Resolution to stage level only. Compiled from Denison (1978), with the exception of taxa from the Gogo Formation of Australia

\begin{tabular}{|c|c|c|c|c|c|c|c|c|}
\hline Dicksonoste & & & & & & & & \\
\hline Holonema & & & & & & & & \\
\hline Buchanosteu & & & & & & & & \\
\hline Homosteus & & & & & & & & \\
\hline Camuropisci & & & & & & & & \\
\hline Rolfosteus & & & & & & & & \\
\hline Tubonasus & & & & & & & & \\
\hline Latocamuru & & & & & & & & \\
\hline Incisoscutum & & & & & & & & \\
\hline Harrytoomb & & & & & & & & \\
\hline Eastmanoste & & & & & & & & \\
\hline Coccosteus & & & & & & & $?$ & \\
\hline Dunkleasteu & & & & & & & & \\
\hline Gorgonichth & & & & & & & & \\
\hline Heintzichthy & & & & & & & & \\
\hline Gymnotrach & & & & & & & & \\
\hline Selenosteus & & & & & & $?$ & & \\
\hline Rhinosteus & & & & & & & & \\
\hline Pachyosteus & & & & & & & & \\
\hline & Ged. & Sieg. & Ems. & Eif. & Giv. & Fras. & Fam. & Tour. \\
\hline & & L. Der & & M. & Dev. & U. I & ev. & Carb. \\
\hline
\end{tabular}


complete specimen of Heintzichthys gouldii (BMNH P9335) from the Natural History Museum (London); this was later restudied by Heintz (1931: figs 3, 5) who presented a reconstruction of the head and thoracic shields. Heintzichthys gouldii is an aspinothoracid arthrodire characterized by internal overlap of the posterior median ventral plate by the anterior median ventral plate and the presence of a posteriorly projecting posterior lateral plate that encloses, in part, the pectoral fenestra.

In 1966 and 1967, the Cleveland Museum of Natural History conducted the Interstate Highway 71 Paleontological Salvage Project. The importance of this project has been twofold: (1) it has added to the known diversity of the Gleveland Shale fauna (Table 2) and (2) it has increased significantly the number of specimens available for study, nearly doubling the Cleveland Museum's collection of Cleveland Shale fishes (Hlavin, 1976). The project provided numerous specimens of Heintzichthys gouldii. The Heintzichthys specimens collected from Interstate 71 , and other material accumulated since Heintz's reconstruction, include isolated dermal plates, partially articulated dermal head and thoracic shields, and perichondrally ossified structures. In addition, the Interstate 71 material provides an ontogenetic series for Heintzichthys gouldii.

This material is important for analysis of the phylogenetic relationships among the eubrachythoracid arthrodires. Miles \& Dennis (1979) suggested that placoderm studies had been burdened by the accumulation of data not directly related to a phylogenetic analysis. Thus, they published a series of descriptive papers on the arthrodires from the Lower Frasnian Gogo Formation, western

TABLE 2. Cleveland Shale vertebrate fauna compiled from Williams (1990) and Hlavin (1976)

\footnotetext{
Arthrodira:

"Dentognathus curvatus" (Havin, 1976)

Bungartius perissus Dunkle, 1947

Callognathus regularis Newberry, 1889

Coccosteus cuyahogae Claypole, 1893

Diplognathus mirabilis Newberry, 1887

Dunkleosteus terrelli (Newberry, 1874)

Glyptaspis verrucosis Newberry, 1889

Gorgonichthys clarki (Claypole, 1892)

Gymnotrachelus hydei Dunkle \& Bungart, 1939

Heintzichthys gouldii (Newberry, 1885)

Holdenius holdeni Dunkle \& Bungart, 1942

Hussakofia minor (Newberry, 1878)

Mylostoma eurhinus (Dunkle \& Bungart, 1945)

Mylostoma newberryi Eastman, 1907

Mylostoma variabile Newberry, 1883

Paramylastoma arcualis Dunkle \& Bungart, 1945

Selenosteus brevis Dean, 1901

Stenosteus glaber Dean, 1901

Titanichthys agassizi Newberry, 1885

Titanichthys attenwatus Wright, 1893

Titanichthys clarki Newberry, 1887

Titanichthys hussakofia Hay, 1929

Titanichthys rectus Claypole \& Wright, 1893

Tracheosteus clarki Newberry, 1889
}

\author{
Chondrichthyes: \\ "Prorodus variabilis" (Hlavin, 1976) \\ Cladoselache acanthopterygius Dean, 1909 \\ Cladoselache brachypterygius Dean, 1909 \\ Cladoselache clarki Claypole, 1893 \\ Cladoselache desmopterygius Dean, 1909 \\ Cladaselache fyleri Newberry, 1889 \\ Cladoselache kepleri \\ Cladoselache magnificus Claypole, 1894 \\ Cladoselache newberryi Dean, 1894 \\ Ctenacanthus clarki Newberry, 1889 \\ Ctenacanthus compressus Newberry, 1878 \\ Diademodus hydei Harris, 1950 \\ Hoplonchus parvulus (Newberry, 1875) \\ Orodus sp. \\ Phoebodus politus Newberry, 1889 \\ Stethacanthus "clevelandensis" (Hlavin, 1976) \\ cladodont (undescribed) \\ Osteichthyes: \\ Kentuckia hlavini Dunkle, 1964 \\ Tegeolepis clarki Newberry, 1888
}


Australia, limiting their discussion to an analysis of 28 phylogenetic characters; little discussion was given to additional anatomical features. In evaluating the relationships of Heintzichthys, it has been found necessary to expand their data matrix. The lack of a more complete description often hinders the analysis of potentially new characters. Evaluation of the eubrachythoracid arthrodires is also hindered by the limited number of published phylogenetic analyses. The phylogenetic utility of any one character cannot be evaluated except through congruence (Patterson, 1982) and should be based on an analysis using all available data.

In the first part of this paper, the anatomy of Heintzichthys gouldii is redescribed in detail. This is followed by a systematic review of brachythoracid arthrodires. The relationships of Heintzichthys gouldii and 17 other brachythoracid arthrodires are evaluated using the computer program, Phylogenetic Analysis Using Parsimony (PAUP version 3.0-Swofford, 1989). Details concerning characters and their polarization and algorithm parameters are discussed in the systematics section. The following taxonomic groups are discussed: brachythoracid, eubrachythoracid, coccosteomorph, pachyosteomorph, aspinothoracid and selenosteid arthrodires, and the family Dinichthyidae. A discussion of eubrachythoracid synapomorphies is included to point out the need for detailed clarification in the presentation of proposed synapomorphies and to rediagnose the eubrachythoracid arthrodires.

Nomenclature and abbreviations, listed here, follow that of Dennis-Bryan (1987). Specimen number prefixes denote their respective institutions: AMNH, American Museum of Natural History, New York; BMNH, Natural History Museum, London; CMNH, Gleveland Museum of Natural History, Cleveland, OH; MCD, Institut de Paléontologie, Paris, MCZ, Museum of Comparative Zoology, Harvard Univ., Boston, MA. The suffix 'id' when used to form taxonomic adjectives does not refer to familial level Linnean classification and is used as a convenience for discussing informal taxonomic units.

\section{MATERIALS}

Specimens, collected before the Interstate 71 Paleontological Salvage Project, are in the collections of the American Museum of Natural History (New York), Buffalo Society of Natural Sciences (Buffalo), Natural History Museum, London, and Cleveland Museum of Natural History (Cleveland). The bulk of Interstate 71 Heintzichthys material was taken from a quarry located at the intersection of West 130th Street and Interstate 71, Brookpark, Ohio. A single shallow horizon, located beneath a thin unconsolidated mud containing numerous pyrite nodules, was the source for numerous fossil fishes found in situ within the shales (Hlavin, personal communication). Field identifications recognized Heintzichthys, 'type W' (a temporary field classification for similar, but unidentified specimens; CMNH 8056, 8057, 8058 and 8059), 'type X' (CMNH 8036, 8037, 8038 and 8039) and 'type Z' (CMNH 8048) material in addition to other recognizable genera. 'Type $W$ ' specimens were later re-identified in the field as belonging to Heintzichthys. 'Type Z, X and W' specimens represent an ontogenetic sequence for Heintzichthys taken from a single horizon within the Gleveland Shale. 


\section{DESCRIPTION}

Heintzichthys gouldii (Newberry)

(Figs 1-18)

\section{Head shield}

General features. The head shield (Figs 1-3) is composed of 15 individual plates; three median unpaired plates $(\mathrm{R}, \mathrm{P}, \mathrm{Nu})$ and six paired plates $(\mathrm{PrO}, \mathrm{PtO}, \mathrm{C}, \mathrm{M}$, $\mathrm{PM}, \mathrm{PNu})$. The marginal plates lack contact with the centrals and the preorbital plates do not meet along the midline. There is no evidence for the presence of postnasal, internasal or extrascapular plates. The orbits are large with an inconspicuous postorbital process. Sensory line canals, when present, are represented by open grooves and will be discussed with the plates on which they occur. The ventral consolidated arches are reduced in comparison with those of Dunkleosteus. Dermal bones typically lack ornamentation; however, ossification centres are discernible through lines of radiation. The plates of the head shield have well developed and interlocking overlaps with the exception of the rostral plate which is often missing.

Rostral (R). This plate (Figs 1, 4A) is triangular in shape with a broad, rounded anterior border. Internally, a ventral anterior thickening is evident (a.th, Fig. 4A), but it is small and continuous, as a low ridge, with the thickening of the opposite side. A similar connecting ridge is seen in Eastmanosteus calliaspis (Dennis-Bryan, 1987: fig. 9A) and is variable in Dunkleosteus terrelli (personal observation). The posterior margin is rounded and possesses a contact surface for the pineal plate (cf.P, Fig. 4A).

Pineal $(\mathbf{P})$. The pineal plate (Figs 1,3 ) overlaps the adjacent preorbital and central plates and lies over the orbit (this position is plesiomorphic at the eubrachythoracid level). There is an anterior overlap area for the rostral plate. The centre of this plate is tuberculated in juvenile specimens with an open pineal foramen (e.g. CMNH 8048). In adult specimens there is an internal closed pineal fossa which is bounded posteriorly by a raised ridge.

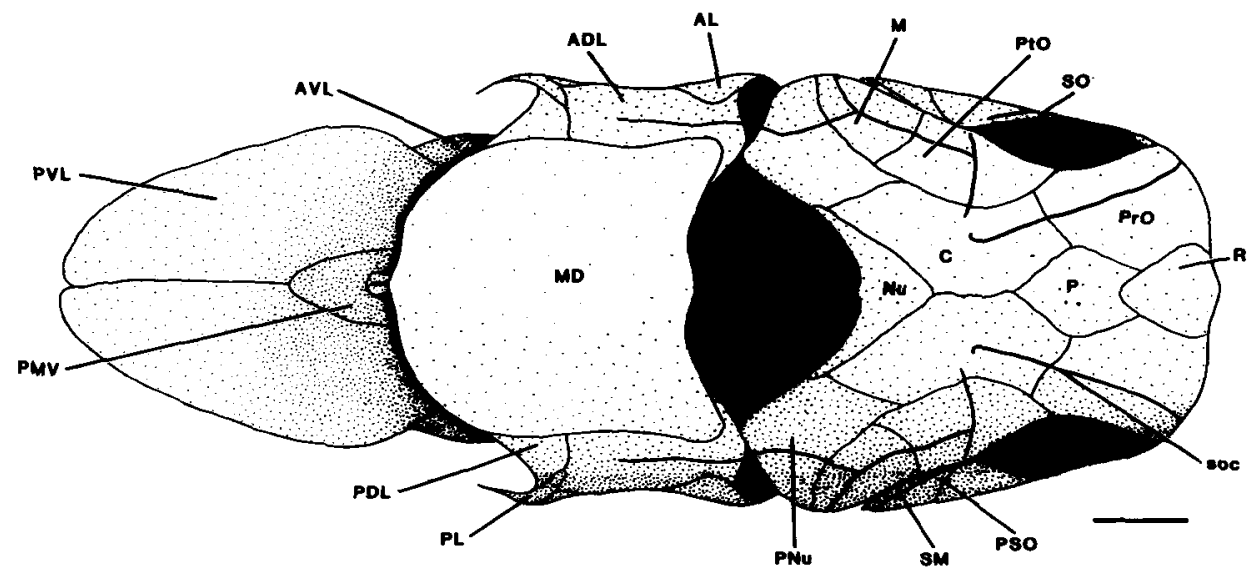

Figure 1. Heintzichthys gouldii. Head and thoracic shields in dorsal view. Scale bar $5 \mathrm{~cm}$. 


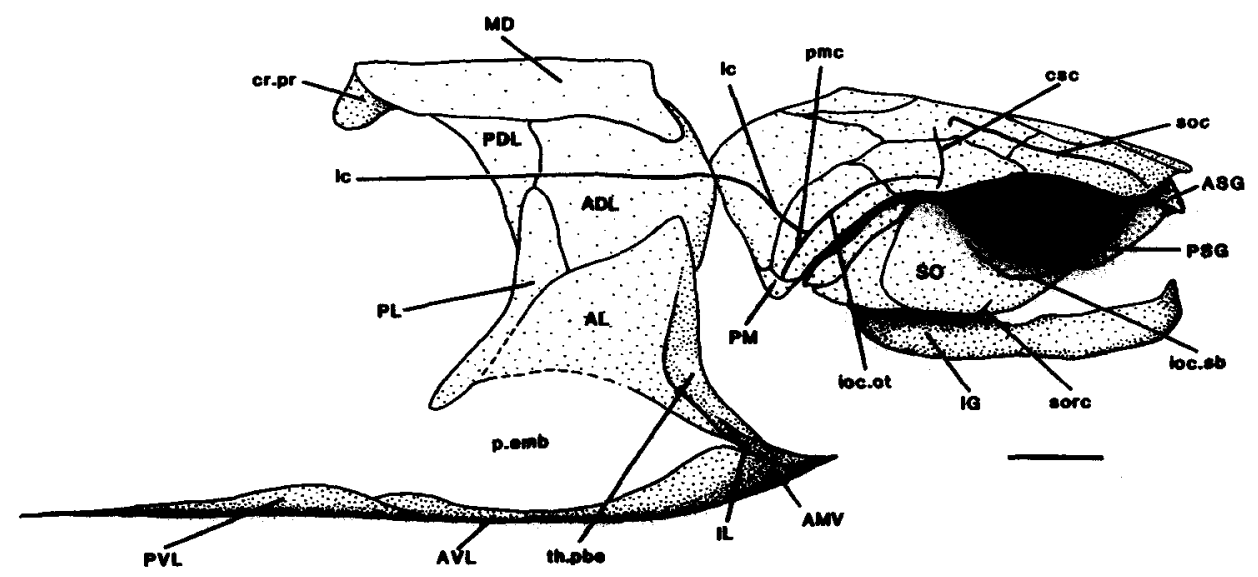

Figure 2. Heintzichthys gouldii. Head and thoracic shields in right lateral view. Scale bar $5 \mathrm{~cm}$.

Nuchal $(\mathrm{Nu})$. The nuchal plate (Figs 1,3 ) is triangular in external view with a deep posterior embayment (shared among aspinothoracid arthrodires with the exception of Gorgonichthys). Juvenile specimens (CMNH 8048, CMNH 8037) possess a transverse anterior border (a convex anterior border in adults is shared among pachyosteomorph arthrodires with the exception of Eastmanosteus calliaspis). A small median posterior process (p.pr, Fig. 3B) is present. The paired pits on the visceral surface of the nuchal (pt.u, Fig 3B, housing processes of the neurocranium) are directed posteroventrally. They are bounded anteriorly by the nuchal thickening (n.th, Fig. 3B, = th.nm of Stensio, 1963: fig. 112) and are separated by a median septum (m.sept). The median septum is continuous with the median posterior process thus separating the transverse thickening into two separate halves. A second pair of pits (probable sites of muscle insertion) is located posterodorsally to the transverse thickening.

Preorbital (PrO). The preorbital plate (Figs 1-3A) possesses a well-developed dermal preorbital process (shared among eubrachythoracid arthrodires and Homosteus). The preorbital plate does not contact its counterpart and is separated by the pineal and rostral plates (this separation is plesiomorphic at the eubrachythoracid level). The groove for the supraorbital sensory canal (soc, Fig. 1) traverses the preorbital plate where it ends on the downturned face of the preorbital process.

The supraorbital vault (suo.v, Fig. 3A), which represents the anterior part of the lateral consolidated part of the head shield, is present on the internal surface and is continuous anterolaterally with the dermal preorbital process. The anteromedial aspect of the supraorbital vault shows a recess (ch.pro.pr, Fig. 3A) for the neurocranial preorbital process. The anterior border of this recess forms the supraethmoid crista (cr.seth, Fig. 3A) which is restricted to the preorbital plate and does not extend on to either the rostral or pineal plates as seen in some selenosteids (e.g. Enseosteus, Stensio, 1963: fig. 113). A deep recess is present anterior to the supraethmoid crista, representing a possible lateral expansion of the olfactory region. The rhinocapsular part of the neurocranium does not appear to be expanded laterally in this region (see discussion of neurocranium). 

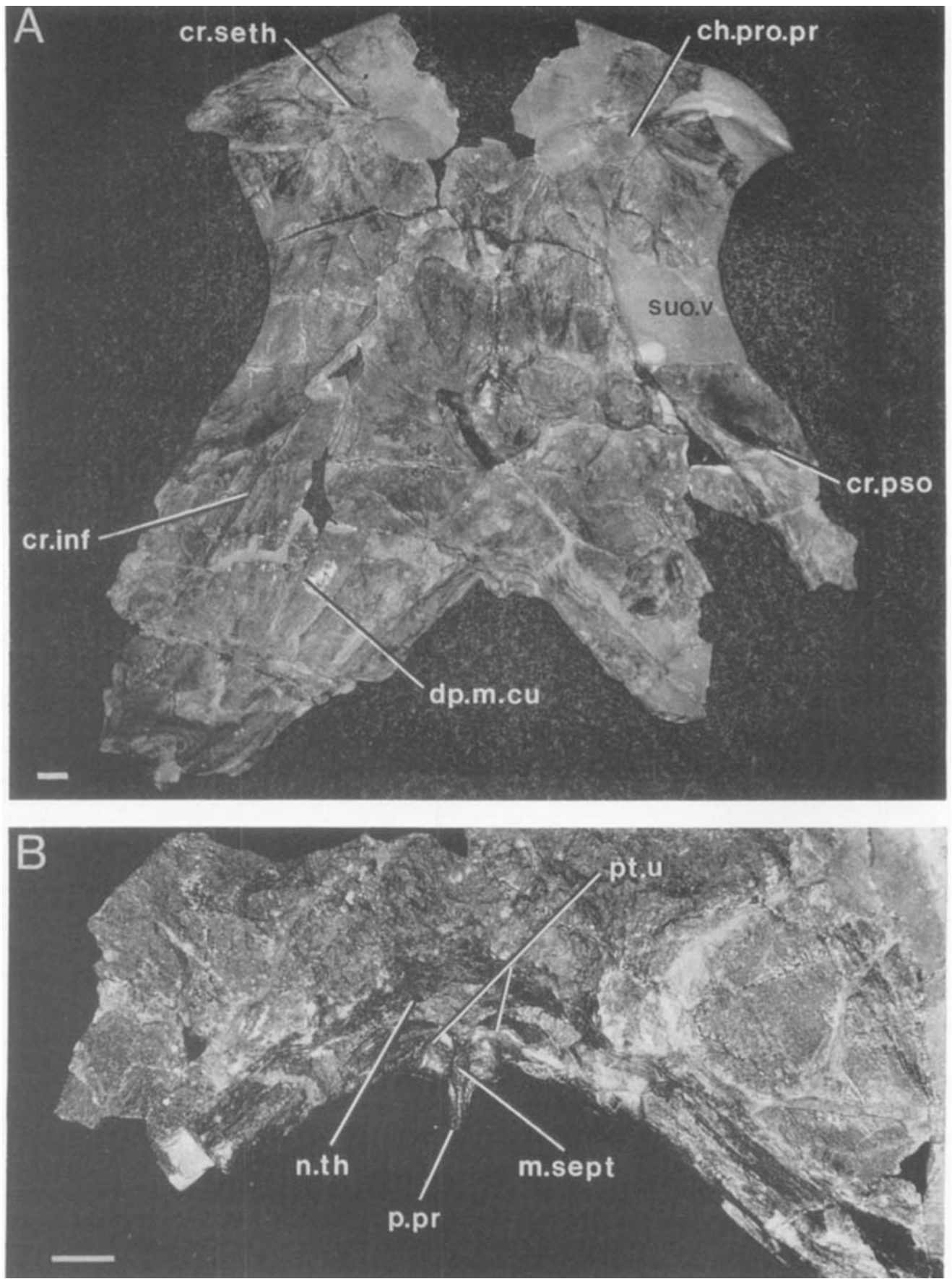

Figure 3. Heintzichthys gouldii. A, Skull roof (CMNH 5648) in ventral view. B, Nuchal thickening (CMNH 5130) in posteroventral view. Scale bars $1 \mathrm{~cm}$. 
Postorbital (PtO) (Figs 1-3A). The dermal postorbital process is poorly developed. Three sensory line grooves are present on the postorbital plate; the central sensory canal (csc, Fig. 2) and the postorbital and otic branches (ioc.ot, Fig. 2) of the infraorbital canal. The groove for the postorbital branch of the infraorbital canal is rotated posteriorly in Heintzichthys gouldii because of the large orbit. This sensory groove terminates prior to reaching the margin of the head shield. A closed angle between the postorbital and otic branches is diagnostic of the aspinothoracid arthrodires (as we will see, this character is independently derived in the camuropiscid arthrodires and Incisoscutum). The angle is further closed among derived aspinothoracids (e.g. selenosteids which have an angle of c. $\left.45^{\circ}\right)$.

The lateral consolidated part of the head shield continues on the internal surface (a short lateral consolidated part of the head shield is synapomorphic for the aspinothoracid arthrodires). A distinct ridge forms the medial border of the supraorbital vault. This ridge continues posterolaterally as the posterior supraorbital crista (cr.pso, Fig. 3A) to the margin of the head shield at a point just posterior to the position of the postorbital branch of the infraorbital canal. The inframarginal crista (cr.inf, Fig. 3A) originates from the supraorbital ridge and continues beneath the main lateral line canal. Heintzichthys lacks a ventral postocular process (= neurocranial process of Heintz, 1932; absence of this feature is plesiomorphic at the aspinothoracid level).

Central (G). The central plates (Figs 1-3A) are separated anteriorly by the pineal plate. Each plate is laterally embayed and overlapped by the postorbital plate. The longitudinal dimension of the central plate is greater than the same dimension of the preorbital plate (a shared feature of Heintzichthys and the remaining derived aspinothoracid arthrodires, excluding Gorgonichthys). Two sensory line grooves are recognized (Figs 1,2); the continuation of the supraorbital canal from the preorbital plate and the central sensory canal. In all specimens the supraorbital canal terminates near the ossification centre in a laterally opening $J$-shape.

Internally, the cuccularis depression (dp.m.cu, Fig. 3A) is bounded anteriorly by a low pre-endolymphatic thickening on the central plate. The anterior margin of this thickening is not discernible.

Marginal (M). The marginal plate (Figs 1-3A) does not contact either the orbit or the central plate (lack of a marginal-central plate contact is present among the aspinothoracid arthrodires with a contact present in Rhinosteus and with Selenostous being polymorphic; orbit-marginal contact is characteristic of selenosteid arthrodires). Three lateral line grooves occur; a continuation of the otic branch of the infraorbital canal, the postmarginal canal (pmc, Fig. 2), and the main line canal (lc, Fig. 2). The groove for the postmarginal canal branches from the infraorbital canal at an angle of $c .120^{\circ}$. It passes to the posterolateral corner of the marginal plate. The marginal plate is overlapped by the paranuchal and postorbital plates.

The inframarginal crista is continued on the internal surface to the ossification centre. A reduced thickening follows the postmarginal canal on the internal surface to the edge of the plate.

Postmarginal (PM) (Fig. 4B). The postmarginal plate forms the posterolateral corner of the head shield. Its external surface bears an overlap area for the marginal and paranuchal plates. The groove for the postmarginal canal extends 

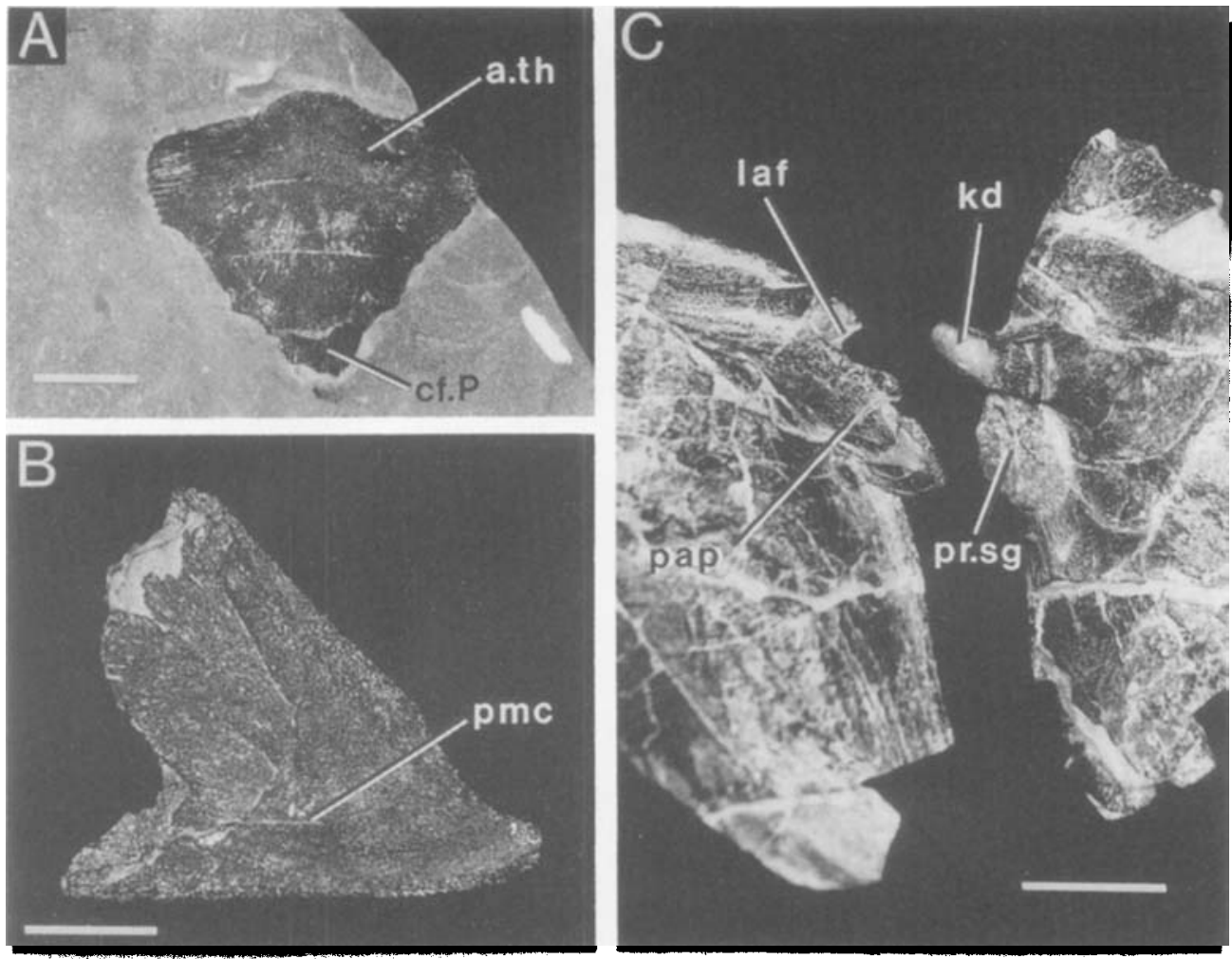

Figure 4. Heintzichthys gouldii. A, Rostral plate (CMNH 9425) in ventral view. B, Postmarginal plate (CMNH 9350) in external view. G, Articular joint between head and thoracic shields (CMNH 6352) in internal view. Anterior dorsolateral and paranuchal plates disarticulated. Scale bars $2 \mathrm{~cm}$.

onto the postmarginal plate (pmc, Fig. 4B). The internal surface lacks any distinctive features.

Paranuchal (PNu) (Figs 1-3A, 4C). The paranuchal plate of juvenile specimens has a postnuchal process (CMNH 8048, CMNH 8037); in adults the process is either absent or very short and limited to the descending posterior face of the head shield. The plate is traversed by the main lateral line groove. A paraarticular process (pap, Fig. 4C) is strongly developed lateral to the articular fossa (laf, Fig. 4G). Internally, the nuchal thickening is continued laterally along the posteromedial border of the paranuchal plate.

\section{Cheek plates.}

General features. The cheeks are composed of three paired plates (SO, PSO, SM) which do not fuse to the head shield. The submarginal plate lies between the suborbital and postsuborbital plates and the head shield.

Suborbital (SO). The suborbital (Figs 1, 2, 5A) is cleaver-shaped with an elongated handle and a short blade. The handle portion sutures with the dermal preorbital process (also seen in pachyosteomorph arthrodires and Harrytoombsia). The general shape is similar to that seen in selenosteids. A short groove for the supraoral sensory canal (sorc, Fig. 2) has been seen clearly only in CMNH 8056. 

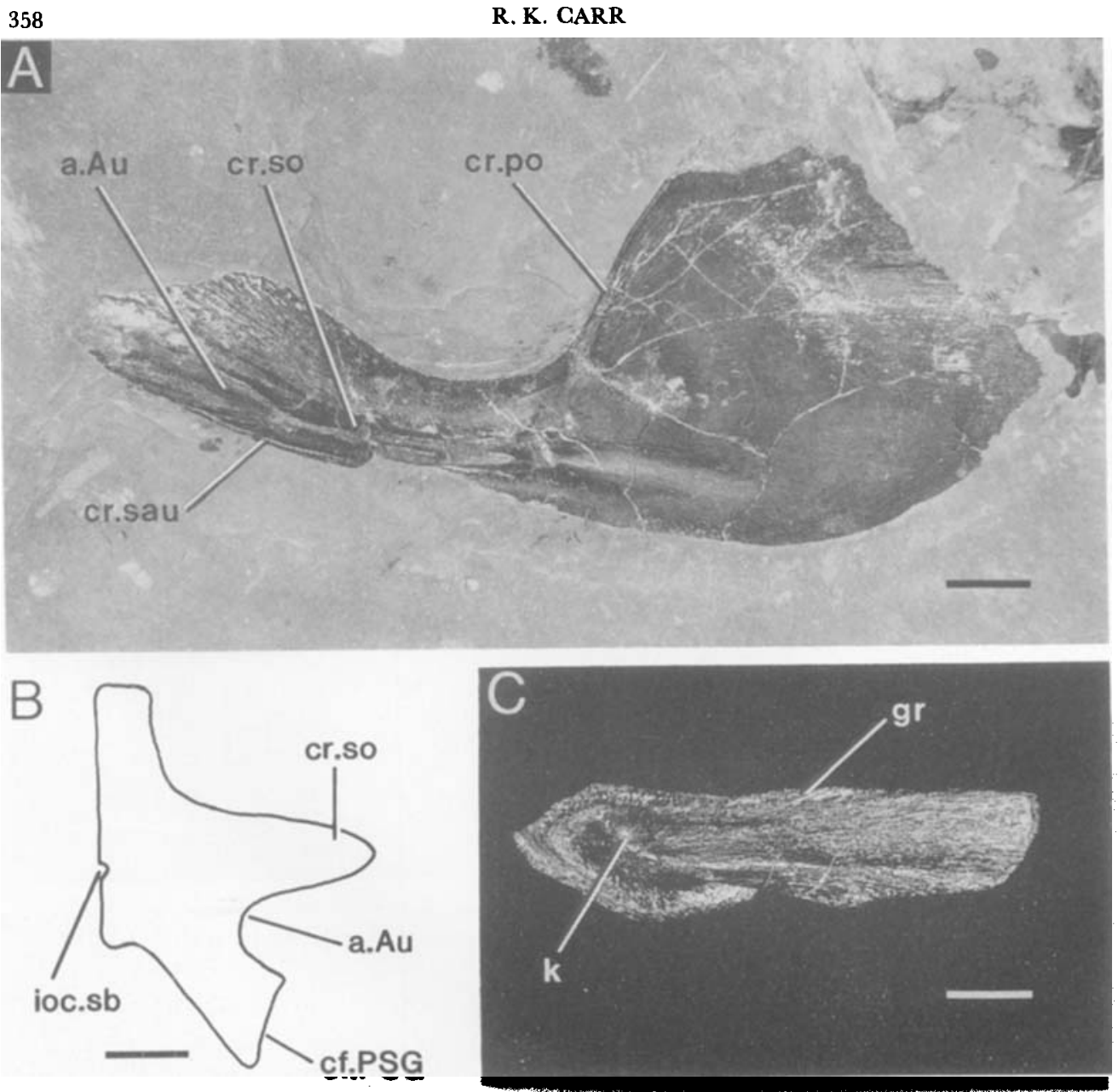

Figure 5. Heintzichthys gouldii. A, C. A, Suborbital plate (CMNH 9332) in internal view. B, Eastmanosteus calliaspis, cross-section of suborbital dermal lamina (BMNH P50894). C, Submarginal plate (CMNH 9407) in internal view. Scale bars $2 \mathrm{~cm}$.

This groove remains close to the posteroventral edge of the suborbital plate and does not connect with the groove for the infraorbital canal. The postorbital groove for the infraorbital canal does not continue to the dorsal edge of the plate (Fig. 2). A suborbital groove is present (ioc.sb, Figs 2, 5B).

The internal surface of the linguiform process (Fig. 5A) is characterized by a well-developed subautopalatine crista (cr.sau, Fig. 5A; = R4 of Heintz, 1932: figs 21,22 ) that lacks a contact surface for the posterior superognathal (cf.PSG, Fig. 5B). The subautopalatine crista continues posteriorly as a low ventral ridge (= R3 of Heintz, 1932: fig. 22) and dorsal to it lies a depression for the autopalatine (a.Au, Figs 5A, B). The subocular crista (cr.so, Figs 5A, B; = R2 of Heintz, 1932: figs 21,22), which is continuous with the postocular crista (cr.po, Fig. 5A; = R1 of Heintz, 1932: fig. 22), dorsally encloses the autopalatine depression. The pattern of these ridges and the autopalatine depression is variable among the eubrachythoracids. In Dunkleosteus, the subautopalatine crista of the sublinguiform process is ventrally enlarged and forms a support 
surface for the posterior superognathal. A similar condition is found in Eastmanosteus calliaspis (Fig. 5B; seen in adult specimens only; see Dennis-Bryan, 1987: figs 9, 13) and Eastmanosteus pustulosus (Boylan, 1973). Heintzichthys gouldii lacks this ventral projection and its subautopalatine crista projects medioventrally, implying that the posterior superognathal articulates solely with the autopalatine and lacks any dermal support. This condition is seen in juvenile specimens of Eastmanosteus calliaspis (personal observation), in Coccosteus cuspidatus (Miles \& Westoll, 1968: fig. 13) and in other aspinothoracids (Melanosteus, Lelièvre et al., 1987: fig. 13; Tafilalichthys, personal observation). At present, the distribution of this character appears to be correlated with a reduction in the depth of the posterior superognathal. The unqualified use of the term 'sublinguiform process' is misleading since it is applied equally to the condition of both Heintzichthys and Dunkleosteus implying homologous states. In addition, it appears that the subautopalatine and suborbital cristae are not clearly distinguished in some cases (e.g. Long, 1988: fig. 13).

Postsuborbital (PSO). The external surface of the postsuborbital plate lacks a sensory canal. Anteriorly, there is an overlap area for the suborbital (oa.SO, Fig. 6A). The posterodorsal edge is slightly recessed, possibly to accommodate the submarginal.

Internally, the location of the quadrate is typically represented by a small ventrally placed thickening; however, the postsuborbital of CMNH 9337 shows a well developed perichondrally ossified quadrate. The condylar area is situated near the ventral edge of the plate. A detent process is present along the dorsal
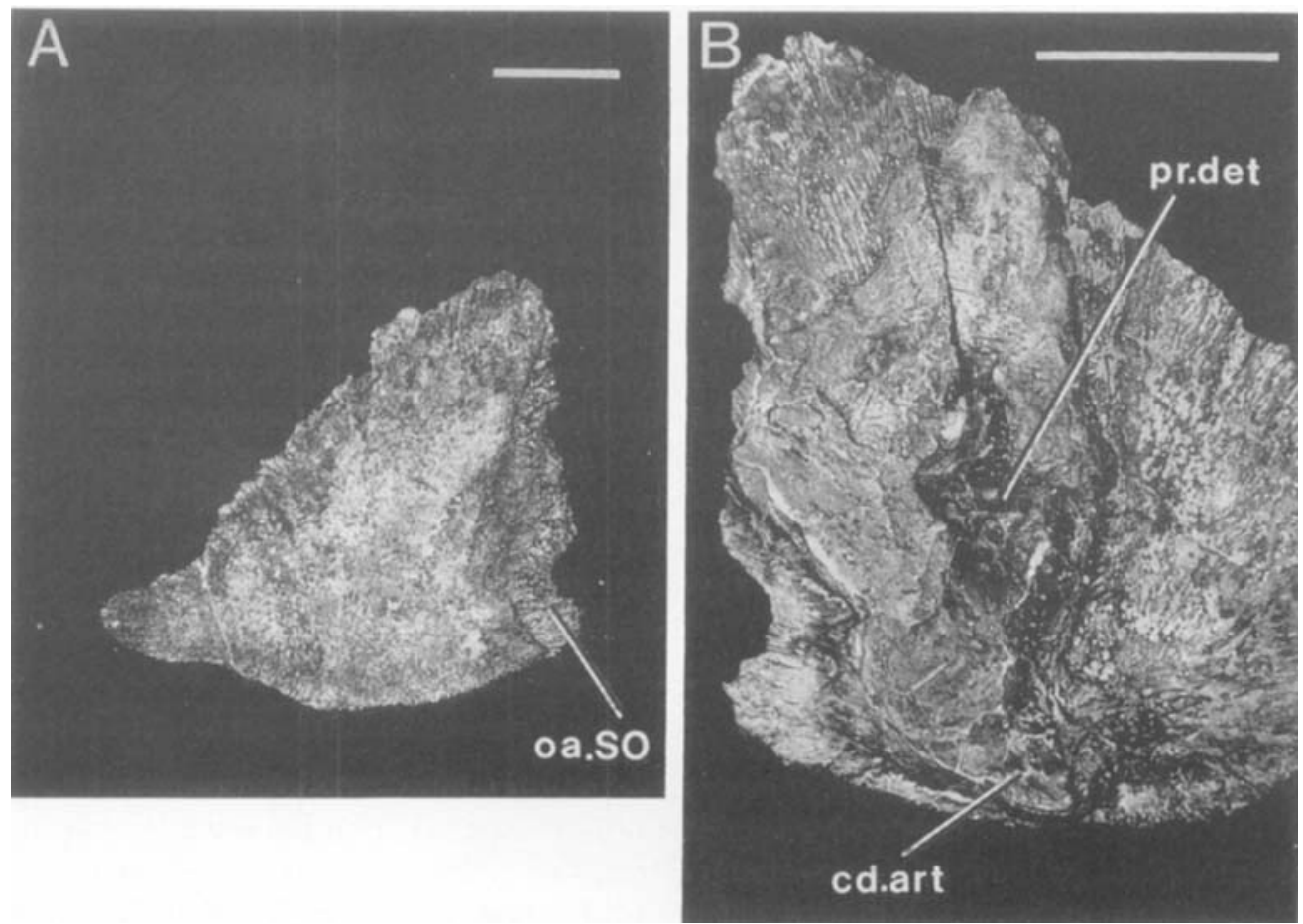

Figure 6. Heintzichthys gouldii. Right postsuborbital (CMNH 9337) in A, external view and B, internal view. Scale bars $2 \mathrm{~cm}$. 
crista of the quadrate (pr.det, Fig. 6B; this appears to be plesiomorphic at the pachyosteomorph level which assumes that the coccosteomorph and pachyosteomorph conditions are homologous).

Submarginal (SM) (Figs 2, 5C). The submarginal plate is elongate and is loosely attached to the head shield (a submarginal plate incorporated into the head shield is seen in selenosteid and camuropiscid arthrodires). Externally, it lacks sensory grooves. Internally, the submarginal is thickened by a longitudinal ridge extending from the anteroventral edge to a posterior thickened $k$ nob ( $k$, Fig. 5C). In specimens with a complete submarginal, the dorsal part of this ridge bears a shallow groove for the hyomandibula (gr, Fig. 5C).

\section{Gnathal plates and parasphenoid}

General features. The gnathal plates include three paired elements: the inferognathals, anterior superognathals and posterior superognathals. The occlusal surfaces of these elements vary with ontogeny. The parasphenoid does not articulate with the anterior superognathal, as it does in Dunkleosteus.

Inferognathal (IG) (Figs 2, 7). The inferognathal can be divided into occlusal (= functional) and blade portions. The occlusal surface represents approximately one half the total length.

Adult inferognathals have a single anterior cusp and a blunt occlusal edge. The angle formed by the occlusal surface and the medial surface of the inferognathal is variable both between specimens and along the occlusal surface of a single individual. This angle ranges from $45^{\circ}$ to $69^{\circ}$. CMNH 8091 and CMNH 5130 have wear striae oriented $99^{\circ}$ and $110^{\circ}$ respectively relative to the occlusal edge and directed anteroventrally from the dorsal edge. The orientation of the striae in these two specimens suggests that the inferognathal was displaced posteriorly relative to the posterior superognathal during closure of the mouth. This represents occlusal variation and is supported by variable wear patterns on the anterior cusp. Ontogenetic variation is evident in CMNH 8093 where the anterior cusp possesses wear surfaces oriented at two distinct angles. There is no indication of a secondary cusp as seen in Dunkleosteus.

Juvenile specimens possess 13 to possibly 15 large and evenly spaced denticles extending from the anterior cusp to the end of the occlusal surface (Fig. 7A). In CMNH 8038 (13 denticles) and CMNH 8037 (14 denticles) there is a small gap Brineer the most anterior denticle and the anterior cusp (possibly a preservational artifact, These denticies are lost anteriorly to posteriorly, due to war with age. There is no evidence for adsymphysial reatcles associated with the antericr cusp and cental field (Crvig, 1580 , dfa.Ig;.

Anterior sufterognathal i $\mathrm{ASG}$, (Figs 2, $8 \mathrm{E})$. The anterior superognathal possesses a posterior process p.pre, Fig. 8E; and a lateral cusp. Unlike Dunkletstiss. Heinizichlys lacks a medial cusp (Orvig, 1980, dfa.ASG;. A depression (ch eth, Fig. 3E is present anterodorsally tor the neurocranial ethmid remina. ithere are no derticles in aciult forms and evidence for their snce in juveniles is unclear. The lateral face is well cieveloped ivion a : isort shelf posterior to the cusp that opposes the inferognathai. The posterior process is poorly developed and is corinuuis with the lateral face as a thin lamina. These conditions are similar to those seen in Gorgonichthys (Dunkle \& Bungart, 1946). 

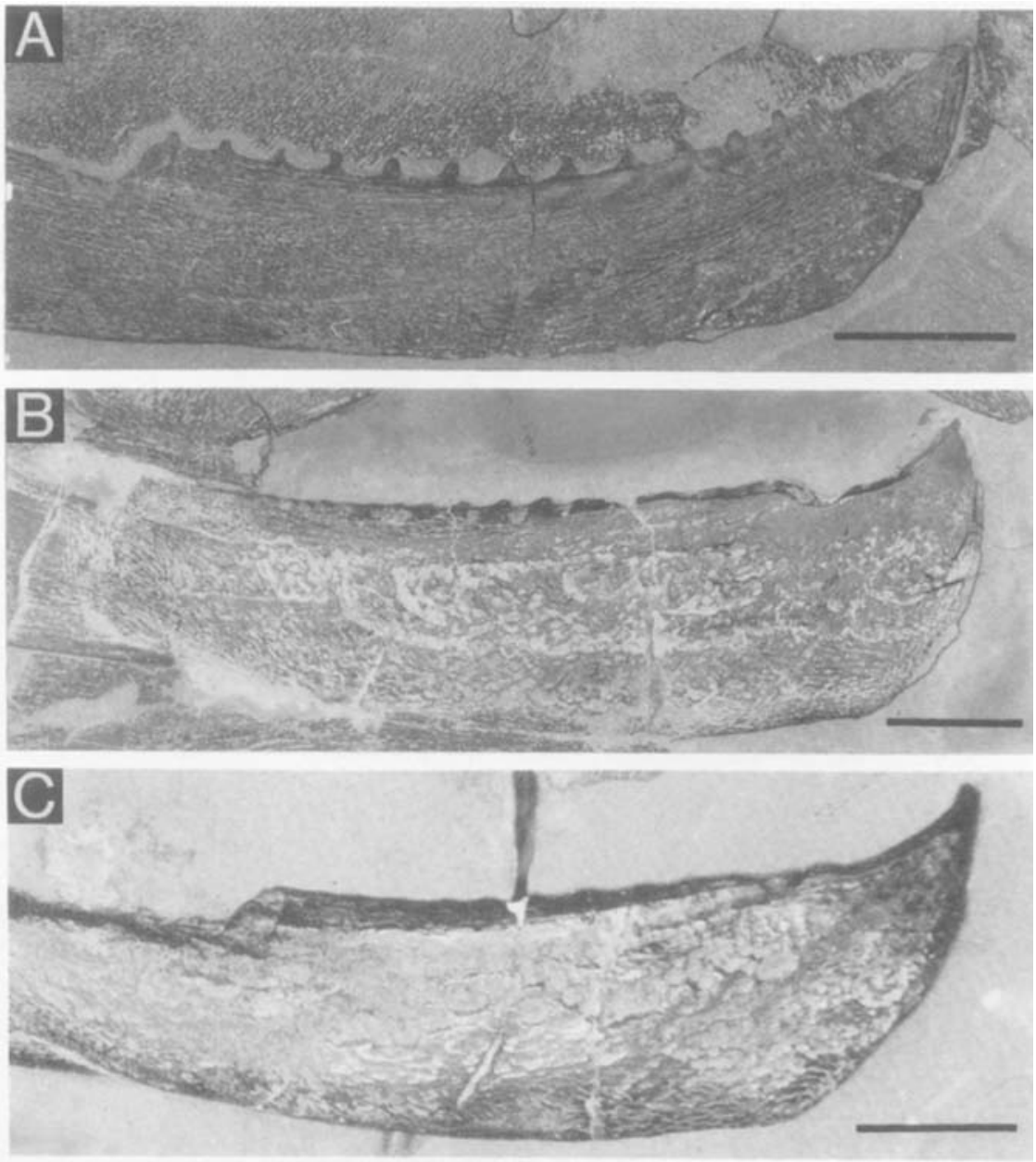

Figure 7. Heintzichthys gouldii. Relative ontogenetic sequence from youngest, A (CMNH 8037, type ' $\mathrm{X}$ '), to an intermediate age (CMNH 8056, type ' $W$ '), and finally to an older age, C (CMNH 8057, type ' $W$ '), showing right inferognathal in external view. Scale bars $1 \mathrm{~cm}$.

Posterior superognathal (PSG) (Figs 2, 8D). The posterior superognathal is shallow and elongate and has a posterior process (p.pro Fig. 8D), THe rat

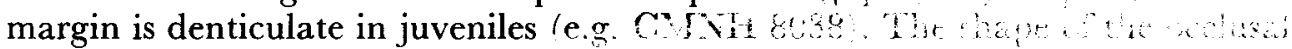

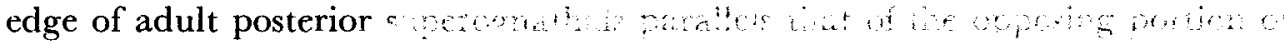
the inferognathal

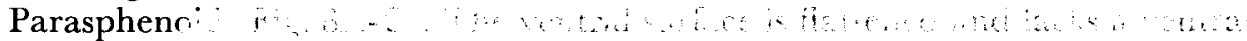
transverse $g$ region (pre:by Stensio

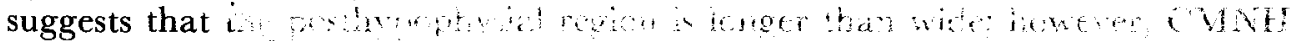

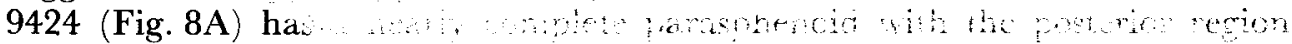

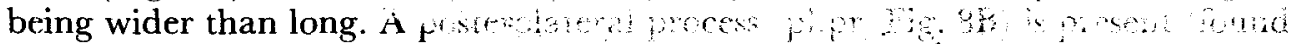

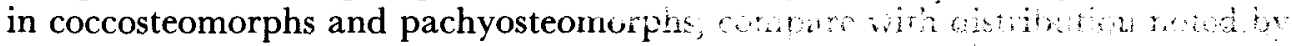
Gardiner \& Miles, 1990, character 22.36). 

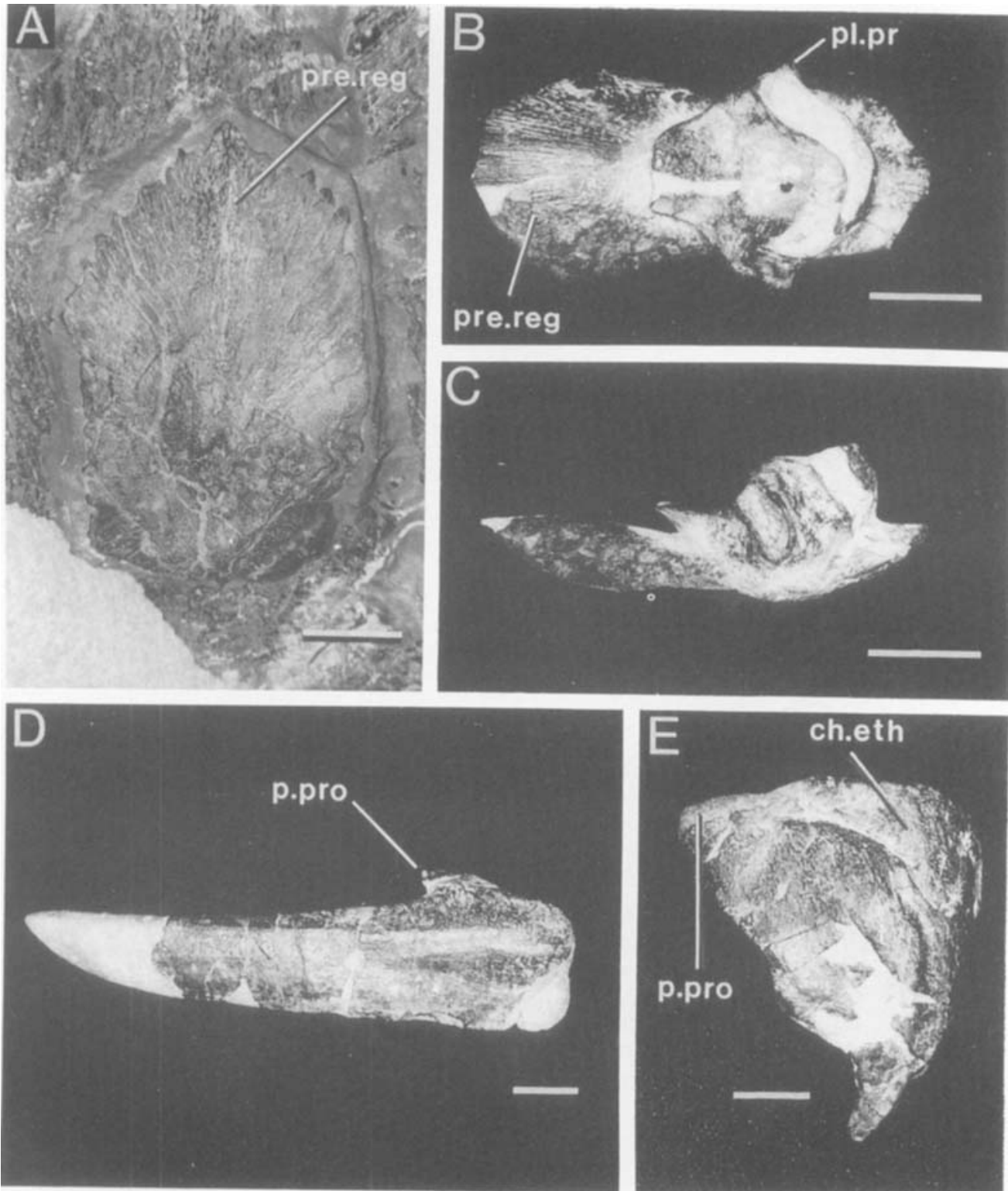

Figure 8. Heintzichthys gouldii. A, Parasphenoid (CMNH 9424) in ventral view. B, Parasphenoid (CMNH 5130) in lateral, and C, dorsal view. Posterior, D, and anterior, E, right superognathals in lateral view (GMNH 5266). Scale bars $1 \mathrm{~cm}$.

\section{Dermal shoulder girdle}

General features. As usual in brachythoracid arthrodires, the dermal shoulder girdle is composed of 17 individual plates; three unpaired median plates (MD, AMV, PMV) and seven paired plates (ADL, PDL, AL, PL, IL, AVL and PVL). The internal surfaces of the ventral plates (AVL, PVL, AMV and PMV) show concentric growth ridges. Externally, juveniles may have a fine tuberculation near the ossification centres of these ventral plates (Dean, 1896). 

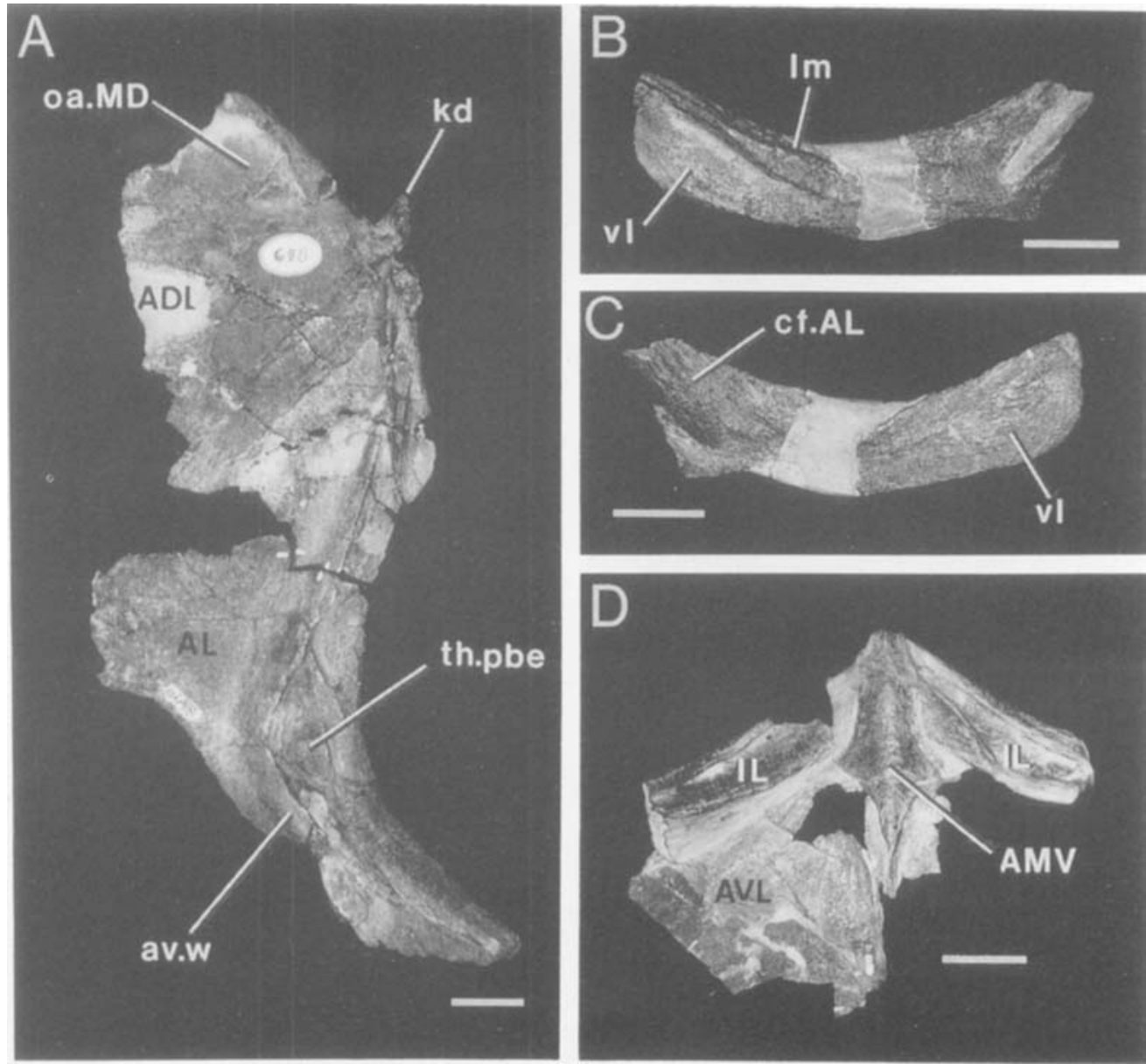

Figure 9. Heintzichthys gouldii. A, Right anterior dorsolateral and anterior lateral plates (CMNH 5130) in lateral view. Left interolateral plate in B, ventral and C, dorsal view (CMNH 7038). D, Anterior median ventral and interolateral plates (CMNH 5130) in ventral view. Scale bars $1 \mathrm{~cm}$.

Median dorsal (MD) (Figs 1, 2, 11). The anterior margin of the median dorsal is embayed with a short, rounded, median process. The posterior margin is rounded. A carinal process (cr.pr, Fig. 2; plesiomorphic at the pachyosteomorph level) is developed and projects posterior to the edge of the plate.

Anterior dorsolateral (ADL) (Figs 1, 2, 4C, 9A, 11). Dorsally, the anterior dorsolateral plate lies deep to the median dorsal plate (oa.MD, Fig. 9A). A process of the anterior dorsolateral plate extends along the anterior edge of the median dorsal plate and forms part of the nuchal gap border. Ventrally, there is a large overlap area for the anterior lateral (Fig. 9A). Anterior to this overlap area, the plate forms part of the postbranchial embayment. The glenoid condyle (kd, Figs 4C, 9A) and the subglenoid process (pr.sg, Fig. 4C) are well developed. The groove for the main lateral line continues horizontally across the surface of this plate and ends prior to the posterior margin.

Posterior dorsolateral (PDL) (Figs 1, 2, 10A, 11). The posterior dorsolateral plate has three overlap areas on its external face; a median dorsal overlap (oa. MD, 

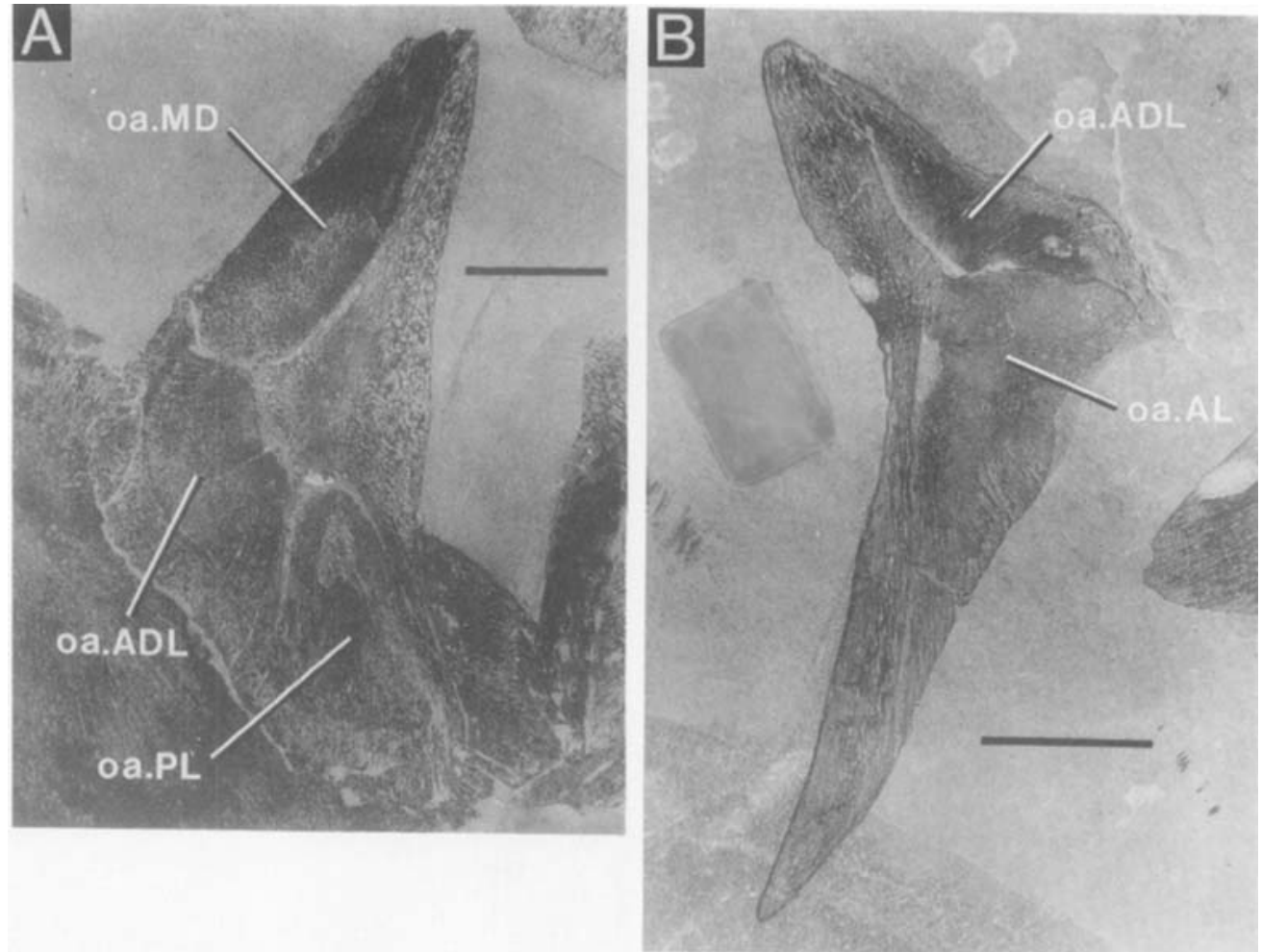

Figure 10. Heintzichthys gouldii. A, Left posterior dorsolateral plate (CMNH 8056, type 'W') in external view. B, Right posterior lateral plate (CMNH 8057, type 'W') in external view. Scale bars $2 \mathrm{~cm}$.

Fig. 10A), an anterior dorsolateral overlap (oa.ADL, Fig. 10A), and a posterior lateral overlap (oa.PL, Fig. 10A). Each overlap area is deeper than the preceding one giving a shingle-like effect with the median dorsal plate overlapping the anterior lateral plate and the anterior lateral plate overlapping the posterior lateral plate. No sensory line grooves are present.

Anterior lateral (AL). (Figs 2, 9A, 11). The anterior lateral plate lacks a dorsal obstantic process (Dennis \& Miles, 1981: fig. 2, pro). The postbranchial embayment (Fig. 9A) extends dorsally from the obstantic thickening (th.pbe, Figs 2, 9A; = th of Heintz, 1932: fig. 51) to the anterodorsal corner of the plate. The embayment is continued on the anterior dorsolateral plate. Ventrally, the postbranchial embayment widens and is continuous with the interolateral plate. The external anteroventral wing of the plate (av.w, Fig. 9A) tapers to its ventral end. The ventral tapering of the anteroventral wing is correlated with the reduction and loss of the spinal plate. The external features of the anterior lateral plate are similar to those in Gorgonichthys (Dunkle \& Bungart, 1946: fig. 2), Titanichthys (Dunkle \& Bungart, 1946) and Tafilalichthys (Lehman, 1956: pl. 2, fig. A).

Posterior lateral (PL). The posterior lateral plate (Figs 2, 10B, 11) is dorsoventrally elongate and forms an obtuse angle which opens posteriorly. There are overlap areas for the anterior dorsolateral (oa.ADL, Fig. 10B) and anterior lateral (oa.AL, Fig. 10B) plates. The ventral portion of the posterior 


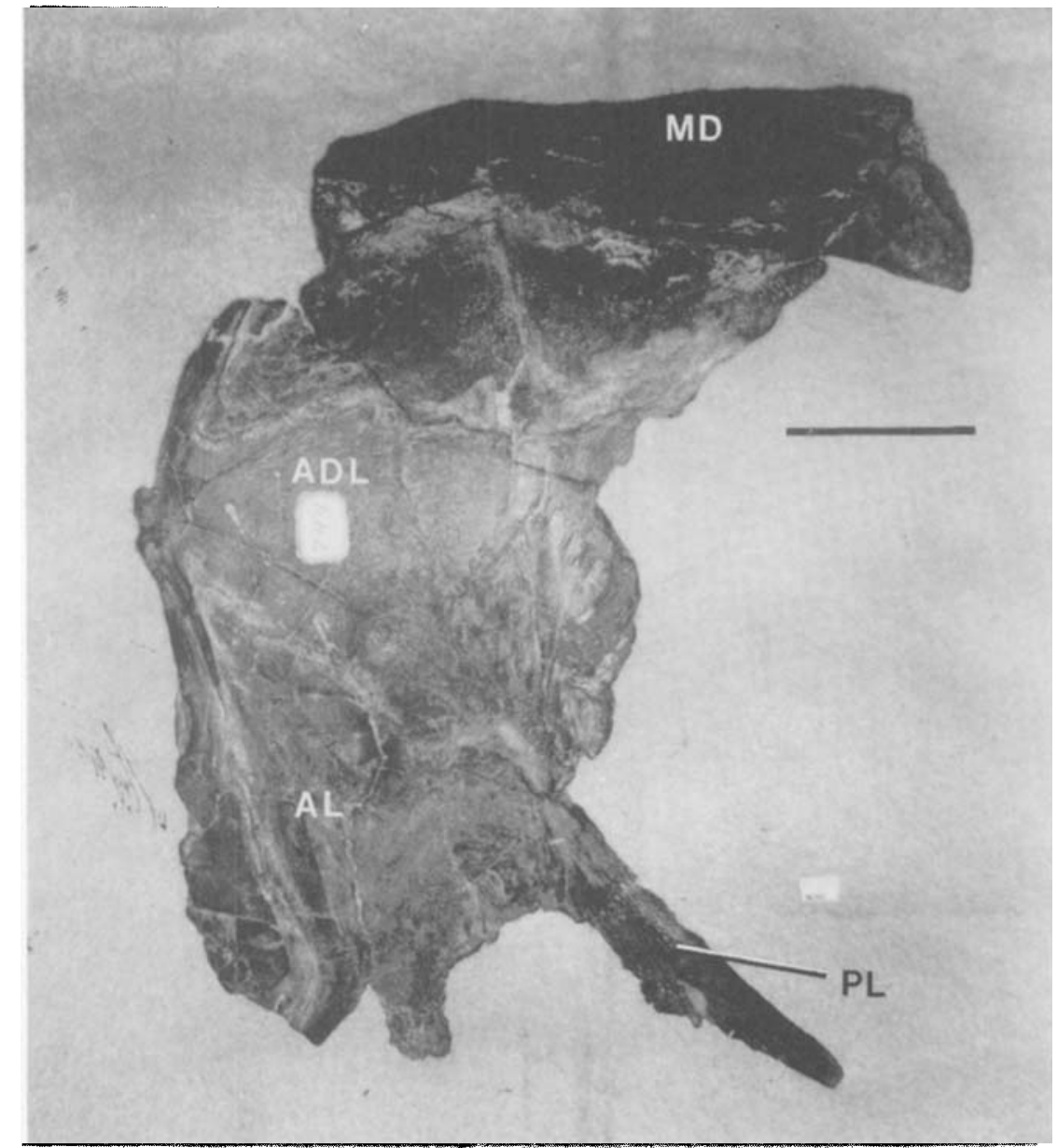

Figure 11. Heintzichthys gouldii. Right side of thoracic shield (GMNH 5744) in lateral view. Scale bar $5 \mathrm{~cm}$.

lateral plate lacks any overlap areas and is free of contacts with adjacent plates and with the ventral shield (Figs 2, 11; diagnostic for Heintzichthys gouldii). This projection of the posterior lateral plate serves to enclose partially the pectoral embayment. The general form of this plate is distinct in all age classes.

Interolateral (IL). The interolateral plate (Figs 2, 9B-D) lacks an anterior ascending lamina (= postbranchial lamina, Denison, 1978), but has a well developed ventral lip (vl, Fig. 9B-D). The surface in contact with the anterior lateral plate is continuous with a thickened lower margin (Fig. 9A; Heintz, 1932). The shape of the thickened lower margin and its contact with the anterior lateral plate (cf.AL, Fig. 9C) is similar to that of Tafilalichthys; however, the interolateral plate of Tafilalichthys lacks a ventral lip (MCD 1). There is no ornamentation on the interolateral plate. The loss of ornamentation and the loss of an anterior ascending lamina represent derived features relative to basal pachyosteomorphs (Eastmanosteus calliaspis and Dunkleosteus terrelli). The orientation of the overlap area on the anterior median ventral plate (oa.IL, Fig. 12A) suggests that the interolateral plates are directed posteriorly from their 

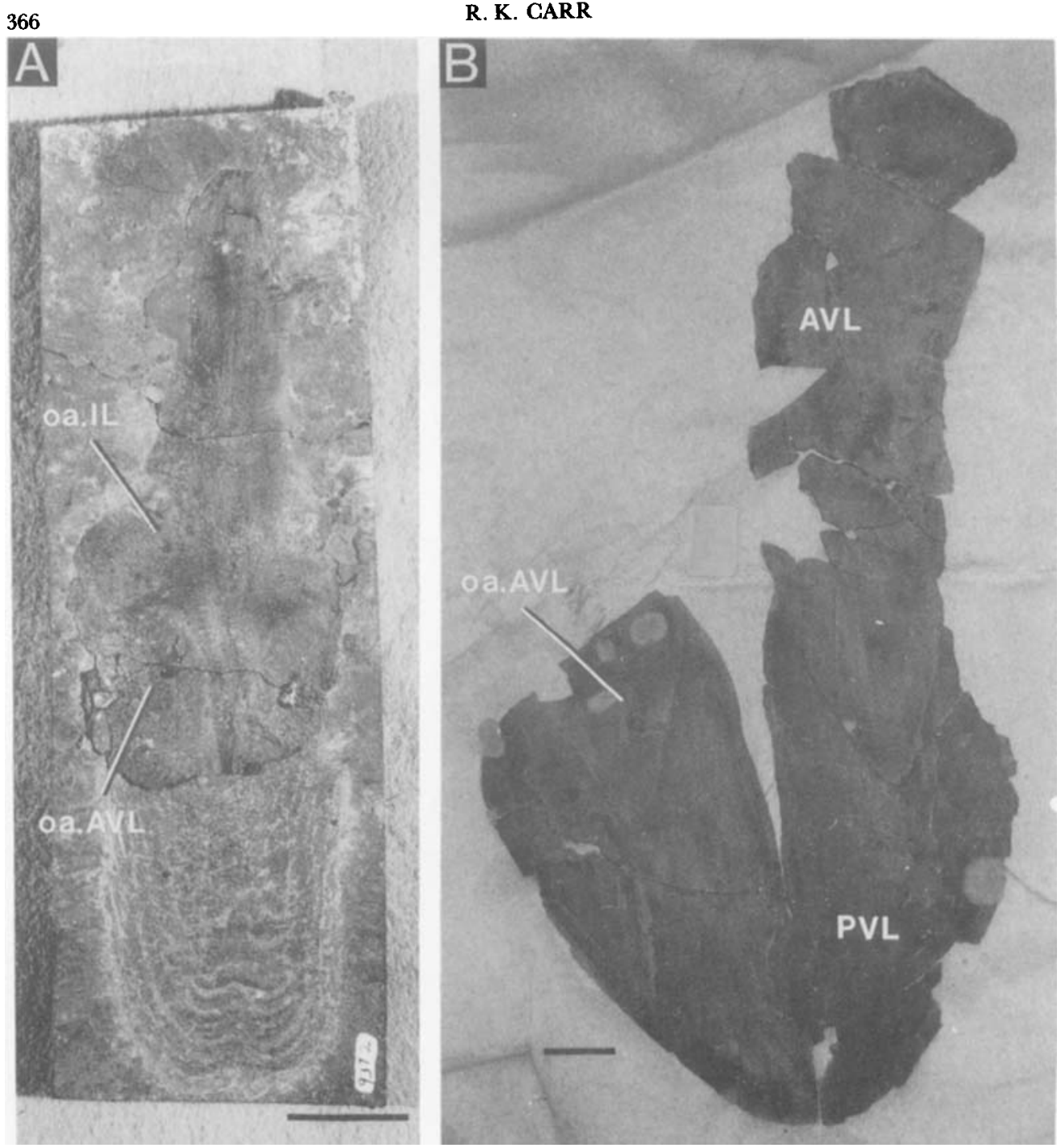

Figure 12. Heintzichthys gouldii. A, Anterior median ventral plate (CMNH 9372) in external view. B, Thoracic ventral shield (CMNH 8057, type 'W') in external view. Scale bars $2 \mathrm{~cm}$.

medial contact with the anterior median ventral plate to their lateral contact with the anterior lateral plate at a $c .45^{\circ}$ angle.

Anterior median ventral (AMV) (Figs 2, 9D, 12A). The external surface bears overlap areas for the interolateral (oa.IL, Fig. 12A), the anterior ventrolateral (oa.AVL, Fig. 12A), and the posterior median ventral plates. The anterior median ventral plate extends anteriorly beyond the anterior ventrolateral plates. This region is the site of distinct overlap areas for the interolateral ventral lip.

Posterior median ventral (PMV) (Figs 1, 13). The posterior median ventral plate has two external overlap areas; the anterior ventrolateral (oa.AVL, Fig. 13A) and the posterior ventrolateral (oa.PVL, Fig. 13A). Internally, it bears a contact face for the anterior median ventral plate (cf.AMV, Fig. 13B). Such a contact face appears to be unique in Heintzichthys, but the presence of this condition in 

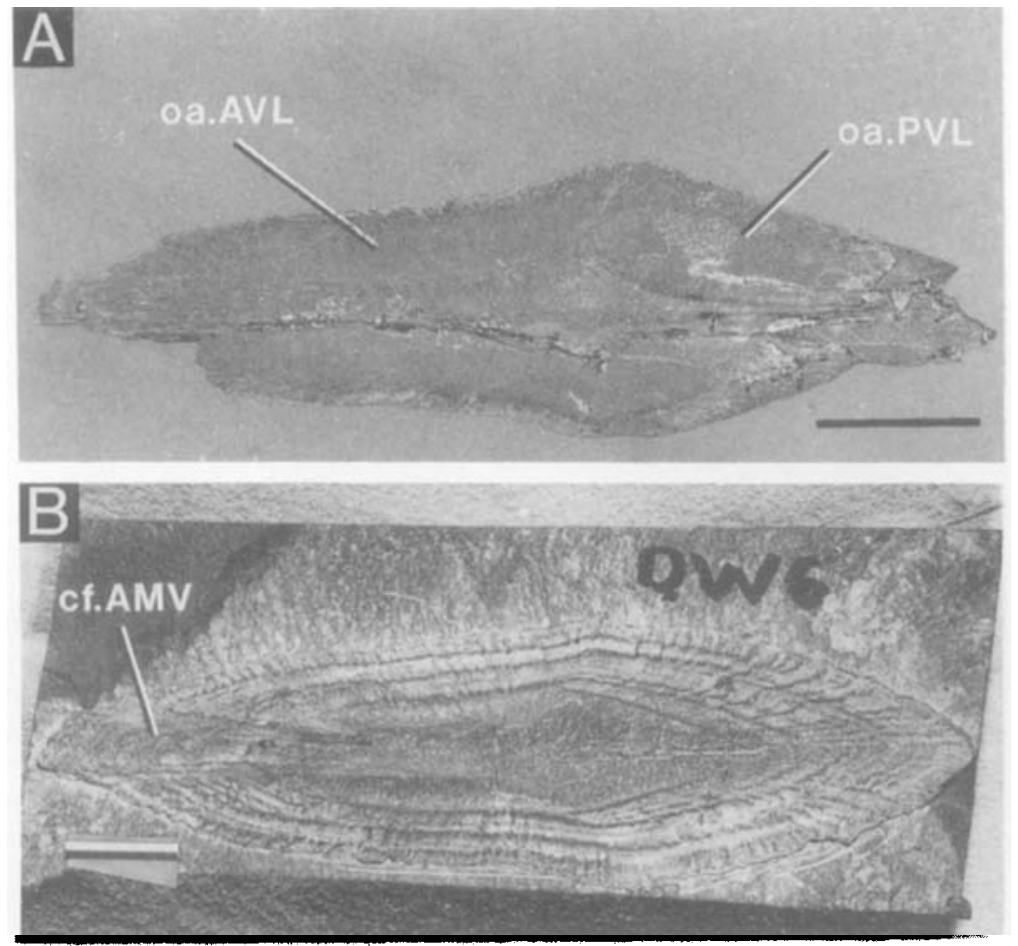

Figure 13. Heintzichthys gouldii. A, Posterior median ventral plate (CMNH 8056, type 'W') in external view. B, Posterior median ventral plate (CMNH 9376) in internal view. Scale bars $2 \mathrm{~cm}$.

potential sister taxa is unresolved due to a lack of knowledge about the nature of these plates.

Anterior ventrolateral (AVL) (Figs 2, 12B, 14A). Internally, the anterior ventrolateral bears an anterolateral Y-shaped thickening, as noted in Eastmanosteus calliaspis (Dennis-Bryan, 1987). The anterior margin of the plate is oblique relative to the midsagittal plane. The $\mathrm{V}$-shaped posterior part of the plate overlaps the posterior ventrolateral plate. A shallow lateral embayment for the pectoral fin is bounded anteriorly by the anterolateral corner of the plate and a distinct posterolateral angle (pl.a, Fig. 14A).

Posterior ventrolateral (PVL) (Figs 1, 2, 12B, 14B). The posterior ventrolateral plate shows an external overlap area for the anterior ventrolateral plate (oa. AVL, Fig. 12B). The right posterior ventrolateral plate may have an overlap for the opposite plate (Fig. 12B).

\section{Pectoral and pelvic fins, axial skeleton and neurocranium}

General features. A number of highly fragmented scapulocoracoids are preserved and are associated with dermal plates from Heintzichthys (e.g. CMNH 9437, 8242). Isolated pectoral and pelvic girdles along with vertebral arch elements are included in the Interstate 71 collection. Several of these specimens were collected from the Heintzichthys horizon (CMNH 9416, 9410 and 9412); however, it is not certain that this material can be assigned to Heintzichthys. 

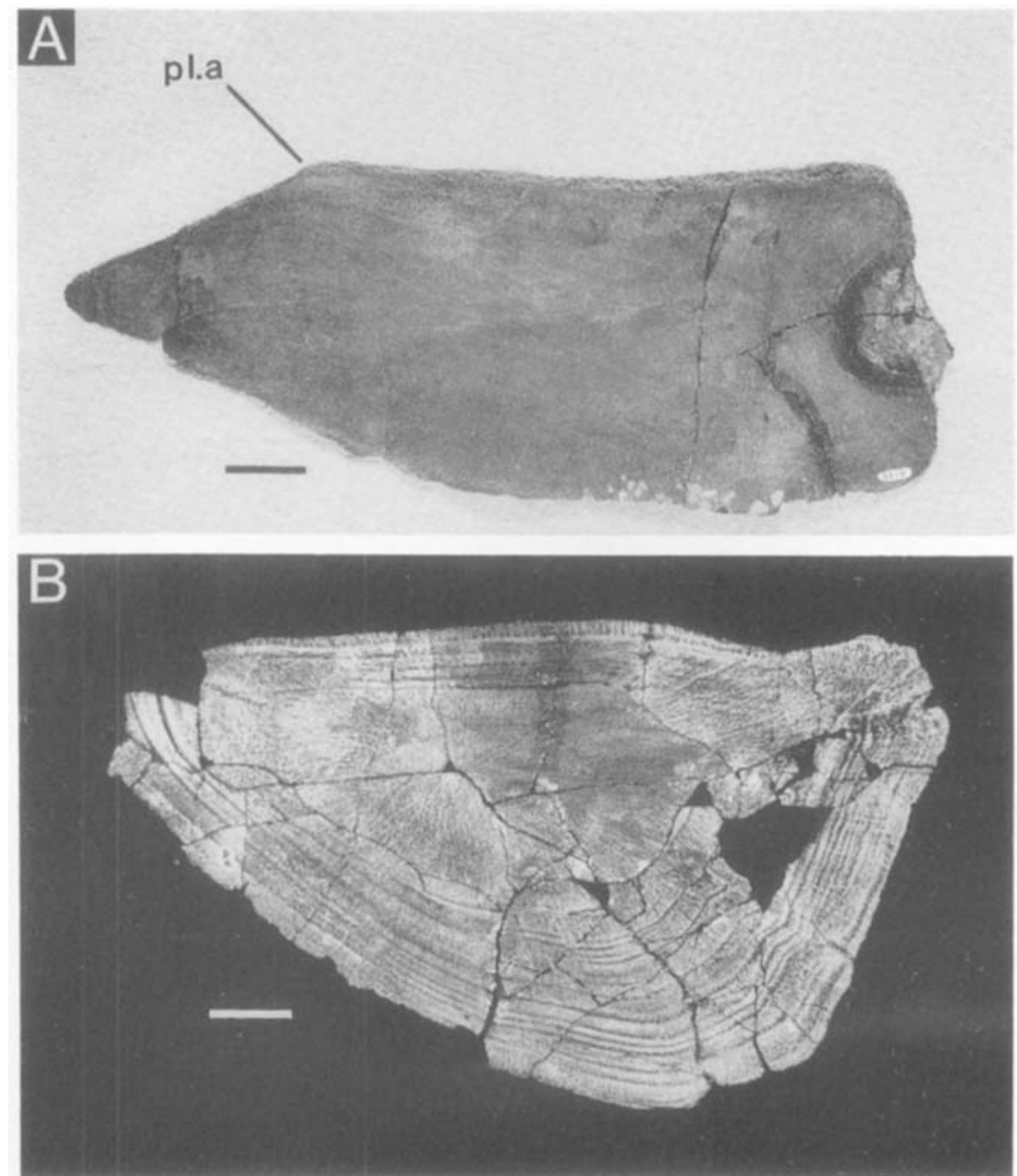

Figure 14. Heintzichthys gouldii. A, Anterior ventrolateral plate (CMNH 9388) in internal view. B, Posterior ventrolateral plate (CMNH 9379) in internal view. Scale bars $2 \mathrm{~cm}$.

Scapulocoracoid. The scapulocoracoid (Fig. 15) is perichondrally ossified in adult specimens. Numerous neurovascular foramina are seen above and below an elongate articular ridge. The edges of the articular ridge (art.cr, Fig. 15A) are scalloped and indicate the presence of a minimum of seven anterior basals with additional posterior basals or a metapterygium; however, the exact count is unclear. The basals are perichondrally ossified and taper distally. They differ from Dunkleosteus, the basals of which are expanded both proximally and distally (Heintz, 1932: fig. 85). CMNH 9411 (Fig. 16A, B), an isolated group of basals from the Heintzichthys horizon, possesses a metapterygium (Met, Fig. 16A, B) and a minimum of eight basals. Four additional, but isolated, metapterygia are associated with Heintzichthys dermal plates (Fig. 16C; in addition CMNH 9354, CMNH 9416 and CMNH 9417). The scapulocoracoid bears muscle scars (m.sc, Fig. 15A) above and below the articular ridge and a number of neurovascular foramina on the anteroventral and dorsal internal surface. 

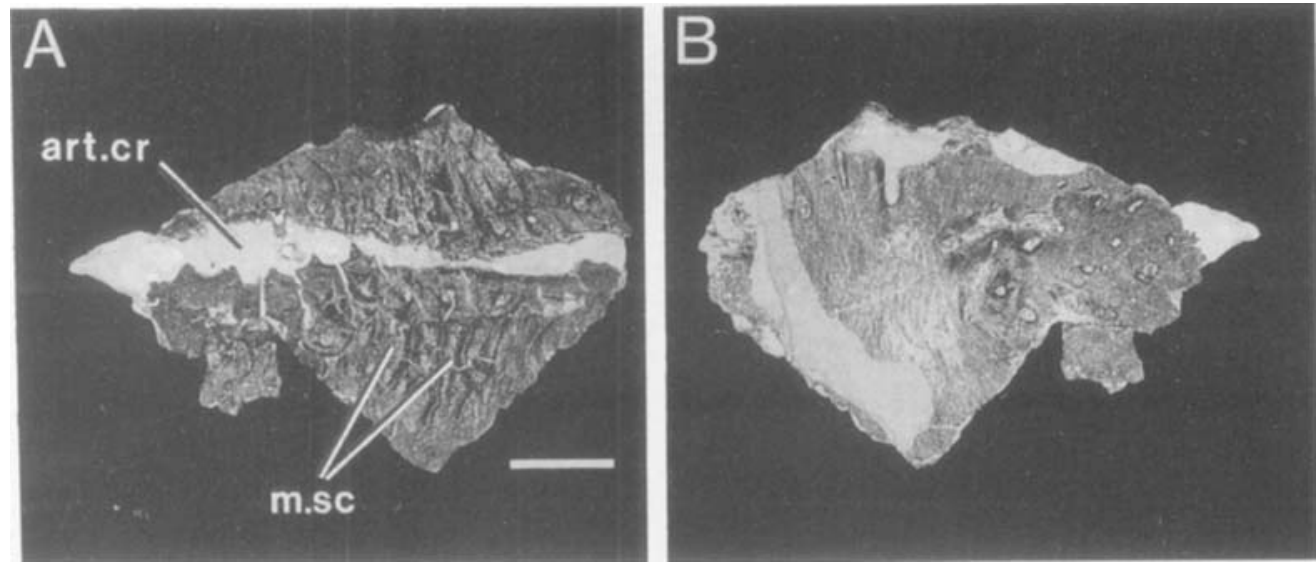

Figure 15. Heintzichthys gouldii. Left scapulocoracoid (CMNH 9401) in A, external and B, internal view. Scale bars $2 \mathrm{~cm}$.
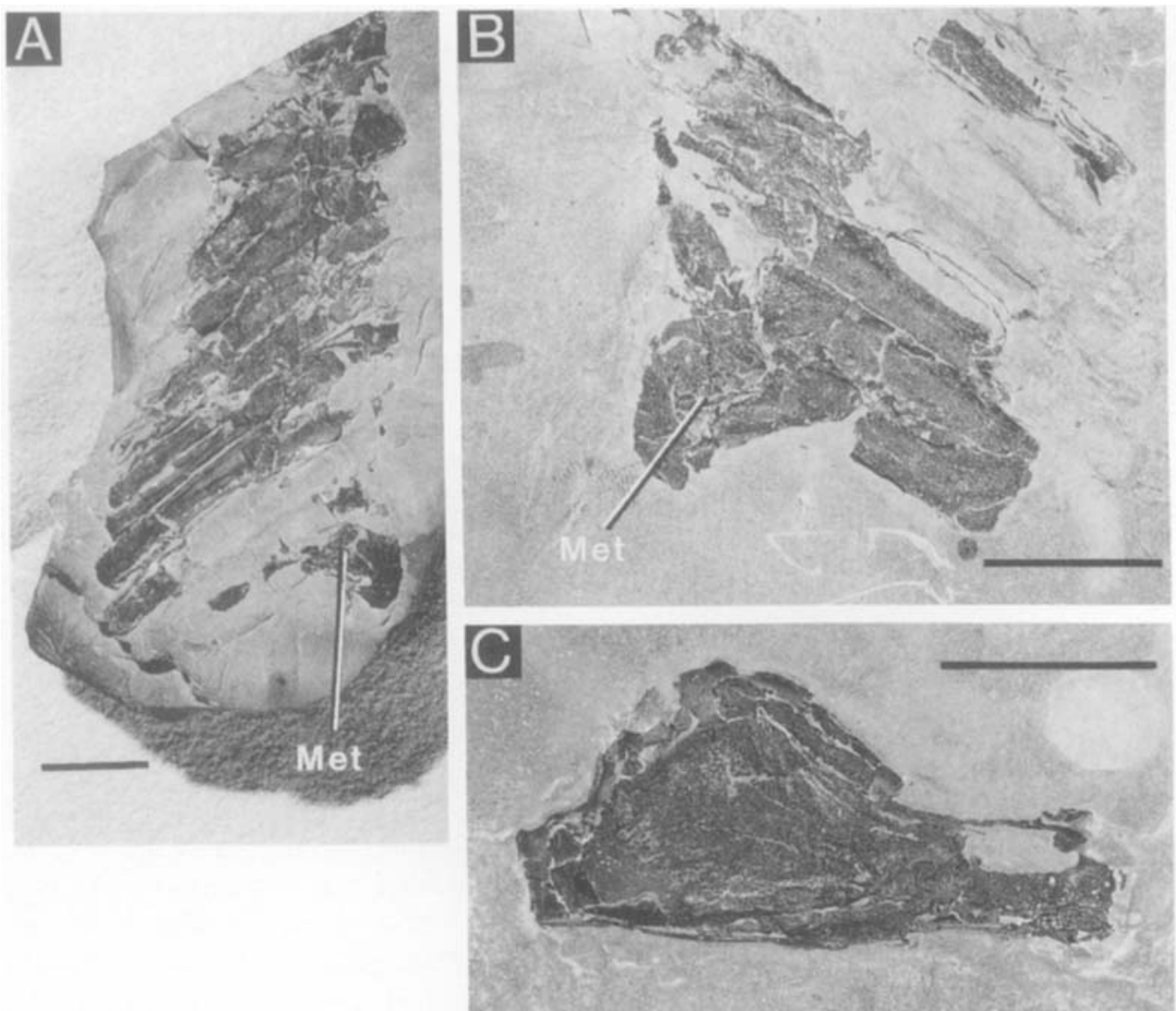

Figure 16. Heintzichthys gouldii. Part, A, and counter-part, B, of pectoral fin basals (CMNH 9411). G, Metapterygium (CMNH 9352). Scale bars $2 \mathrm{~cm}$. 

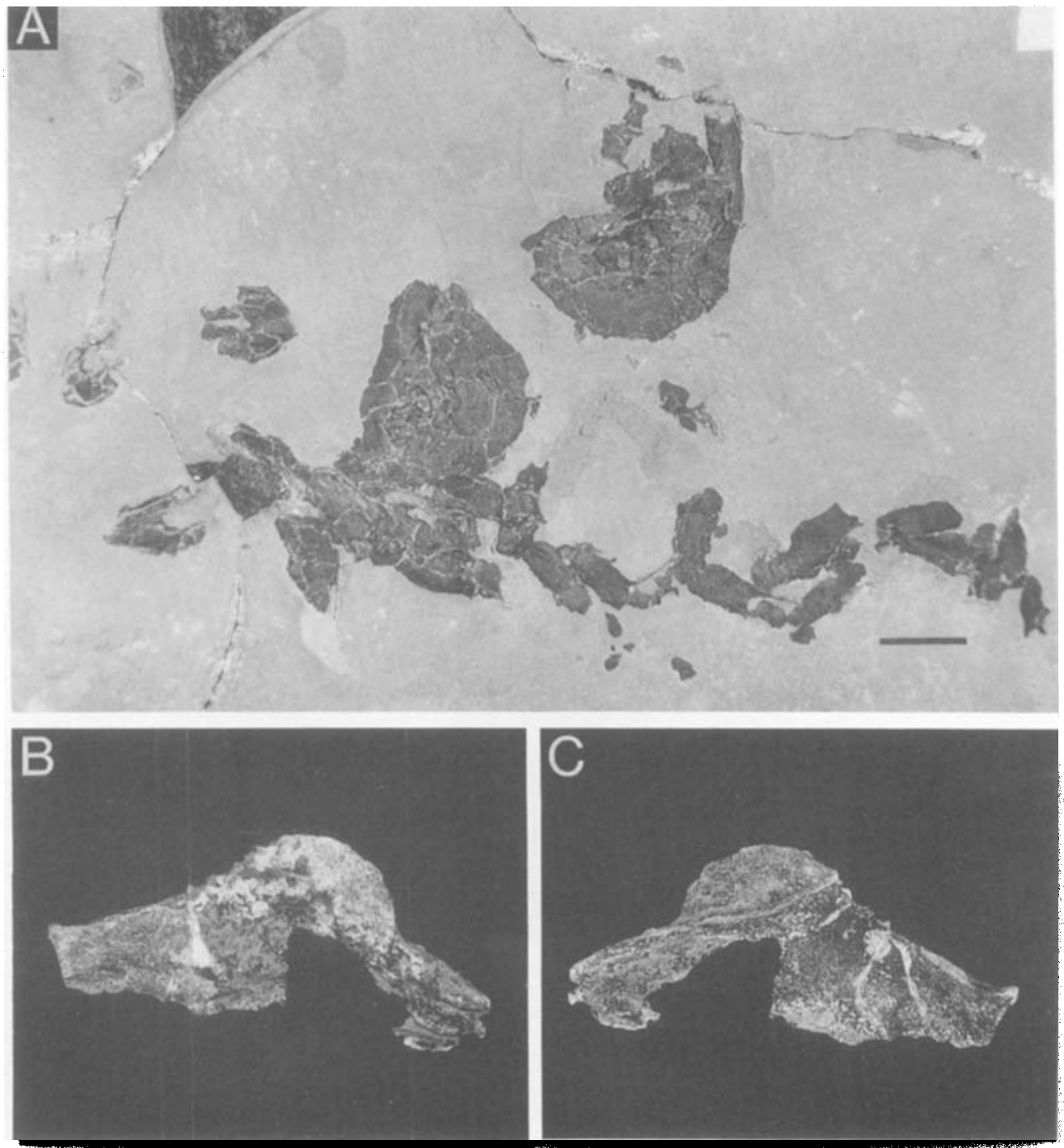

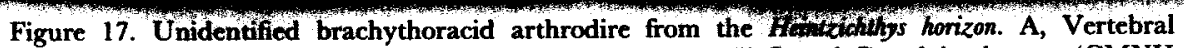
elements and pelvic girdle (CMNH 9416). Heintzichthys gouldii. B and C, pelvic element (CMNH 7111 ). Scale bars $2 \mathrm{~cm}$.

Pelvic fin. A single Heintzichthys specimen (CMNH 7111, Fig. 17B, C) possesses a poorly preserved bone that appears to be a pelvic fin with an anterior thickened ridge and iliac process (Dennis-Bryan, 1987: fig. 30, rdg.a, pr.il). No other pelvic girdles are known from clearly identified Heintzichthys specimens. Within the collections from the Cleveland Museum of Natural History are two specimens of pelvic girdles associated with vertebral elements (Fig. 17A and CMNH 9412). These were collected from the Heintzichthys horizon and were identified in the field as belonging to Heintzichthys; however, the basis for this identification is unclear since no original field notes are available and the specimens are not associated with any identifiable Heintzichthys material. Despite 


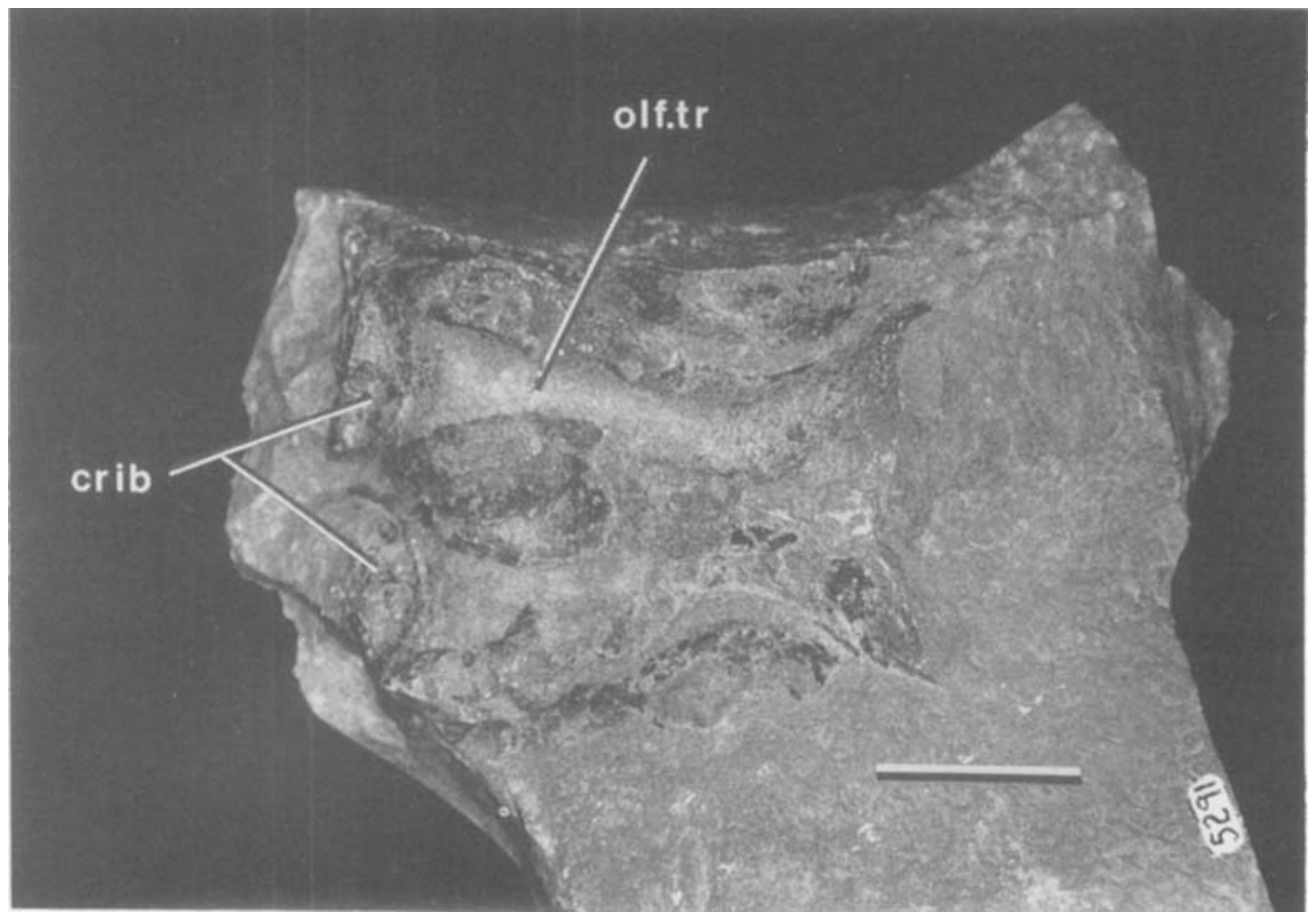

Figure 18. Heintzichthys gouldii. Frontal section of neurocranium and nasal capsules (CMNH 5291). Scale bar $2 \mathrm{~cm}$.

the lack of evidence to associate them with Heintzichthys, the pelvic girdles are interesting since they consist solely of paired basal plates and lack a thickened anterior ridge and iliac process.

Vertebral elements. Vertebrae bear neural and haemal arches and spines (Fig. 17A; Dean, 1896: Plate VII); however, their detailed structure is unclear.

Neurocranium. A single neurocranium (Fig. 18) is known for Heintzichthys and is associated with a complete sclerotic ring. The neurocranium has been split along the frontal plane. Two medially positioned cribrosal bones (crib, Fig. 18) are present. Spaces for the olfactory tracks (olf.tr, Fig. 18) project posteriorly from the nasal capsules. Lateral to the cribrosal bones can be seen the anterolateral preorbital processes. Owing to the nature of preservation and splitting along the frontal plane, other details cannot be clearly identified at this time and must await further non-destructive analysis. Of interest to this discussion is the lack of a lateral expansion in the region of the deep recess anterior to the supraethmoid crista.

\section{A SYSTEMATIC REVIEW OF BRACHYTHORACID ARTHRODIRES}

\section{Introduction}

The systematics of brachythoracid arthrodires has been in a state of flux although the relationships of various subgroups within the Arthrodira have been studied. Topics covered were the interrelationships among the Arthrodira (Denison, 1984; Gardiner \& Miles, 1990), the 'primitive' brachythoracids 
(Lelièvre, 1984a, b, 1988), the eubrachythoracid arthrodires (Miles \& Dennis, 1979; Dennis \& Miles, 1979a, b, 1980, 1981, 1982), and the family Camuropiscidae (Long, 1988). The present study allows evaluation of Heintzichthys and leads to a cladistic analysis using PAUP (Swofford, 1989). Eighteen brachythoracid taxa and one phlyctaeniid arthrodiran taxon are analysed utilizing 85 characters (Appendix). Dicksonosteus, one of the better known phylctaeniid arthrodires (Goujet, 1984), is used as an outgroup. Dicksomosteus and the 'primitive' brachythoracids (Holonema, Homosteus and Buchanosteus) are included in the present analysis to establish a polarity of characters within the eubrachythoracid arthrodires. All characters are analysed as unordered. These characters are presented below and represent adult features.

\section{Character descriptions}

\section{HEAD SHIELD}

1. Nuchal plate with posterodorsally placed paired pits (f.lv of Goujet, 1984): absent $(0)$, present on the paranuchal plate in Holonema; present (1).

2. Posterolateral extension of the lateral consolidated arch: extends as a distinct ridge or thickening onto postmarginal plate or to the head shield edge if the postmarginal plate is absent $(0)$; extends onto the marginal plate (1); absent (2).

3. Triangular depression posterior to supra-orbital vault (character 14, in part, of Dennis \& Miles, 1979b): absent (0); present (1).

4. Neurocranial process or thickening (character 16, in part, of Dennis \& Miles, 1979b): absent (0); thickening (1); distinct process (2).

5. Rostral plate posterior development: not developed (0); subtriangular (1); T-shaped (2).

6. Anterior elongation of the rostrum (fig. 18, character 3, in part, of Dennis \& Miles, 1979b; characters 4, 12, and 16, of Long, 1988): absent (0); present (1).

7. Ventrally enclosed tubular rostrum: absent (0); present (1).

8. Position of anterior edge of pineal plate: over orbit $(0)$; anterior to orbit (1).

9. Position of posterior edge of pineal plate: over orbit $(0)$; posterior to orbit (1).

10. Shape of the external anterior nuchal border: straight $(0)$; convex (1); concave (2).

11. Shape of the posterior nuchal border: straight (0); convex (1); concave (2).

12. Nuchal thickening (Levièvre, 1988): discontinuous with the lateral thickening associated with the cranio-thoracic dermal articulation $(0)$; continuous thickening across the posterior head shield (1).

13. Preorbital plate embayment of the central plate: absent (0); shallow (1); developed (2).

14. Paranuchal plate embayment of the central plate: absent $(0)$; shallow, determined by formation of the lateral lobe and not the posterior lobe (1); developed (2).

15. Ratio for the external longitudinal lengths of the preorbital and central plates $($ ratio $=\operatorname{PrO} / \mathrm{C}$ ): subequal, i.e. $0.75<r<1.25(0)$; preorbital plate longer, i.e. $r>1.25(1)$; central plate longer, i.e. $r<0.75$ (2). 
16. Postnasal plate infrafenestral process (character 22.18 of Gardiner \& Miles, 1990): absent (0); present (1).

17. Preorbital plate with a dermal preorbital lamina or process (character 19 of Dennis \& Miles, 1979b): absent (0); present (1).

18. Preorbital plates with a median contact (modified after character 19a of Young, 1981): contact posterior to pineal (0); contact anterior to pineal (1); pineal separates preorbital plates (2).

19. Extent of median preorbital plate contact: short $(0)$; long, measured as the (ratio of contact length)/(PrO parasagittal length) (1).

20. Postorbital plate embayment of central plate: absent $(0)$; shallow (1); developed (2).

21. Length of central plate contact with the nuchal plate: short $(0)$; long, measured as greater than one half the length from the nuchal anteromedian point to the posterolateral corner of the nuchal plate (1).

22. Width of the central plate at its contact with the pineal plate: central plate tapers anteriorly to contact $(0)$; central plate expanded laterally to produce a transverse anterior border (1).

23. Marginal plate in contact with the central plate (character 5 of Lelièvre, 1988): present $(0)$; absent (1).

24. Extent of marginal plate along the lateral border of the head shield: less than half the length from the postorbital process to the posterolateral corner of the head shield $(0)$; greater than half the length $(1)$.

25. Marginal plate forms part of orbit border (character 26 of Dennis \& Miles, 1979a): absent (0); present (1)

26. Postnasal plate forms part of orbit border (fig. 18, character 1 of Dennis \& Miles, 1979b): absent (0); present (1).

27. Extent of postnasal involvement in the orbit border: minimal $(0)$; developed (1).

28. Orbit size: measured as a ratio of (distance between preorbital and postorbital dermal processes)/(distance between pineal and paired condyles) small (0); intermediate (1); large (2).

29. Nuchal and paranuchal plates elongate (Lelièvre, 1984b): absent (0); present, associated with elongation of the endolymphatic canal (1).

30. Postnuchal process of paranuchal plate on dermal surface (modified after character 8, of Dennis \& Miles, 1979a): absent (0); present (1), indicated by the presence of a postnuchal process on the dermal surface of the head shield.

31. Position of the central/paranuchal/marginal or postorbital triple point relative to paranuchal/central/nuchal triple point: $\mathrm{C} / \mathrm{PNu} / \mathrm{M}$ or $\mathrm{PtO}$ posterior to $\mathrm{PNu} / \mathrm{C} / \mathrm{Nu}(0)$; anterior $(1)$.

32. Position of preorbital/postorbital/central triple point relative to posterior triple point $(\mathrm{PtO} / \mathrm{M} / \mathrm{C}$ or $\mathrm{PtO} / \mathrm{PNu} / \mathrm{C})$ : parallels the midline or with the anterior point lateral $(0)$; posterior point lateral to anterior point (1).

33. Position of $\mathrm{PrO} / \mathrm{PtO} / \mathrm{C}$ triple point relative to the orbit: posterior to orbit (0); over the orbit (1).

34. Postorbital dermal process: negligible or absent $(0)$; present (1).

35. Median dorsal plate with a ventral ridge (combination of characters 4 and 18 of Dennis \& Miles, 1979a): a ventral thickening or ridge (0); posterior ridge with a posterior process, not spatulate (1); posterior process posterodorsally spatulate (2). 


\section{THORACIC SHIELD}

36. Median dorsal plate shape (width/length): short and broad to equidimensional $(0)$; body of plate long and narrow, whose measure does not include a posteriorly produced spine (1).

37. Median dorsal plate posterior border (character 18, in part, of Dennis \& Miles, 1979a): rounded (0); spinous (1).

38. Anterior lateral plate/anterior ventrolateral plate contact: absent $(0)$; present (1).

39. Anterior lateral plate/interolateral plate external contact: absent $(0)$; present (1).

40. Interolateral/spinal lateral contact: absent (0); present (1).

41. Pectoral dermal enclosure: fenestra $(0)$; embayment open posteriorly (1).

42. Posterior lateral plate and posterior dorsolateral plate overlap (Vézina, 1988): simple overlap (0); insertion (1).

43. Posterior lateral plates forms part of closed pectoral fenestra: absent (0); present (1).

44. Posterior lateral plate ventral lamina (character 22.13 of Gardiner \& Miles, 1990): absent (0); present (1).

45. Spinal plate (Stensio, 1959); absent (0); present (1).

46. Spinal plate spinal pit (character 22.32 of Gardiner \& Miles, 1990): absent (0); present (1). Gardiner \& Miles distinguish between the presence of a reduced spinal pit ('pseudo-spinal' of Miles, 1971) and the presence of a developed pit which both represent the site of a lateral pre-pectoral endochondral process (e.spi, Stensio, 1959). The latter condition is found in Coccosteus and Harrytoombsia and is assumed to be primitive; however, the distribution of this character in both their study and the current study suggests that the lateral pre-pectoral process in eubrachythoracids is independently derived.

47. Interolateral plate brachial lamina: absent (0); present (1).

48. Interolateral plate ventral lamina: small or absent $(0)$; developed with either an enlarged contact with the anterior median ventral plate or an enlarged overlap with the anterior ventrolateral plate ( 1 .

49. Interolateral plate branchial lamina ornamentation: absent $(0)$; present $(1)$.

50. Posterior ventrolateral plate dorsolateral contact with the lateral thoracic shield: posterior lateral plate only $(0)$; posterior lateral and anterior lateral plates (1).

51. Posterior ventrolateral plate postpectoral lamina (character 22.8 of Gardiner \& Miles, 1990): absent (0); small (1); large (2).

\section{CHEEK AND PALATOQUADRATE}

52. Suborbital dermal lamina (character 17 of Dennis \& Miles, 1979a): absent (0); present (1).

53. Suborbital plate overlaps postorbital plate (character 22.9 of Gardiner \& Miles, 1990): absent (0); present (1).

54. Suborbital/preorbital contact: absent (0); lateral contact (1).

55. Suborbital and marginal plates in contact (character 22.28 of Gardiner \& Miles, 1990): absent (0); present (1). 
56. Suborbital plate with a contact face for the PSG (cf.PSG) on the linguiform process (cr.lg): absent $(0)$; present $(1)$.

57. Palatoquadrate ossifications (character 21 of Dennis \& Miles, 1979a): ossified as a single unit (0); autopalatine and quadrate ossifications (1).

58. Detent process on quadrate (character 22.1 of Gardiner \& Miles, 1990): absent (0); present (1). Gardiner \& Miles (1990) suggest that a supraglenoid process and therefore, a dentent process are present in Coccosteus based on the development of the articular dorsal to the inferognathal. In the present study, this character is considered as unknown. The a posteriori position of Coccosteus might suggest the presence of these processes based on a parsimony argument; however, the current morphological evidence is not clear.

59. Submarginal plate closely associated with the hyomandibular: absent $(0)$; present, indicated by the presence of perichondral bone or the presence of an internal depression (1).

60. Form of submarginal plate: broad (0); elongate (1).

61. Length of cheek and head shield contact: long $(0)$; short, measured as the contact being less than one third of the length measured from the anterior suborbital plate to the posterior cheek/head shield contact (1).

62. Development of cheek/head shield overlap: loose contact $(0)$; well bound contact, indicated by the interdigitation of plates or their complete fusion (1).

\section{PARASPHENOID AND GNATHAL ELEMENTS}

63. Inferognathal with a developed blade portion (modified after character 13 of Dennis \& Miles, 1979a): absent (0); present (1).

64. Inferognathal anterior dental field developed anteriorly of the cusp region: absent $(0)$; present (1), indicated by a projection of the inferognathal anterior to dorsal functional region.

65. Adsymphyseal (anterior dental field) denticles: absent (0); present (1).

66. Anterior superognathal cusps: none (0); lateral (1); lateral and anterior (2).

67. Anterior superognathal plate with an enclosed lateral face: absent $(0)$; present (1).

68. Anterior superognathal plate with a dorsal process (character 22, in part, of Dennis \& Miles, 1979a): absent (0); present (1).

69. Dorsal process of the anterior superognathal plate forms an open ring (modified after character 4, of Lelièvre et al., 1981): ring open, measured as greater than $90^{\circ}(0)$; ring forms a $c .90^{\circ}$ angle (1); ring closed, measured angle less than $90^{\circ}(2)$.

70. Posterior superognathal plate with a dorsal process (character 22, in part, of Dennis \& Miles, 1979a): absent (0); large (1); small (2).

71. Width/length ratio for the parasphenoid pre- and posthypophysial shelf: prehypophysial shelf width greater than length, posthypophysial shelf width greater than length $(0)$; prehypophysial shelf width less than length, posthypophysial shelf width greater than length (1); prehypophysial shelf width greater than length, posthypophysial shelf width less than length (2); prehypophysial shelf width less than length, posthypophysial shelf width less than length (3). 
72. Parasphenoid posterolateral process (character 22.36 of Gardiner \& Miles, 1990): absent (0); present (1).

73. Median hypophysial vein foramen (character 22.7 of Gardiner \& Miles, 1990): absent (0); present (1).

74. Parasphenoid ventromedian crest (character 22.27 of Gardiner \& Miles, 1990): absent (0); present (1). Gardiner \& Miles presented this feature as a synapomorphy of the coccosteomorph arthrodires; however, Dennis \& Miles did not note this feature in their descriptions of Camuropiscis (Dennis \& Miles, 1979a), Rolfosteus and Tubonasus (Dennis \& Miles, 1979b). In addition, this feature is also present in Eastmanosteus calliaspis (Dennis-Bryan, 1987, cr.m, fig. 17).

\section{SENSORY CANAL GROOVES}

75. Angle between the postorbital and otic branches of the infraorbital sensory canal groove (modified after character 5 of Lelièvre et al., 1987): open posteriorly, i.e. the formed angle is greater than $90^{\circ}(0)$; partially closed, i.e. the formed angle is between $45^{\circ}$ and $90^{\circ}$ (1); closed, i.e. the formed angle is less than $45^{\circ}(2)$.

76. Central canal groove meets supraorbital groove: absent $(0)$; present (1).

77. Ventral groove of the main lateral line on the anterior dorsolateral plate (lc.vl of Miles, 1971: fig. 108): absent (0): present (1).

78. Dorsal groove of the main lateral line on the posterior dorsolateral plate (ld of Miles, 1971: fig. 108): absent (0); present (1), distinguished from the main lateral line groove by its dorsal trajectory or its continuation onto the median dorsal plate.

79. Main lateral line groove on the posterior dorsolateral plate (lc of Miles, 1971: fig. 108): present (0); absent (1).

80. Dorsal groove of the main lateral line on the median dorsal plate (ld of Miles, 1971: fig. 108): absent (0); present (1).

81. Postorbital sensory line groove on suborbital plate (character 1 of Lelièvre, 1988): absent (0); present (1).

82. Angle between the suborbital and postorbital branches of the infraorbital sensory line groove (Lelièvre, 1984a): open (0); closed, measured as less than $90^{\circ}(1)$.

83. Postorbital branch of the infraorbital sensory line groove and supraoral sensory groove confluent (Lelièvre, 1984a): discontinuous (0); continuous (1).

84. Supraorbital canal extended onto central plates: absent $(0)$; present (1).

85. Postmarginal canal: absent $(0)$; present (1).

\section{Algorithm parameters and results}

Analysis using PAUP ('hold trees' set at ten) gives seven equally parsimonious trees. A strict consensus tree is presented in Fig. 19A. These results are dependent upon choice of outgroup and choice of algorithm parameters; however, Fig. 19B represents a strict consensus summary of all possible combinations using 'primitive' brachythoracids (Holonema, Buchanosteus and Homosteus) and Dicksonosteus as outgroups. In the latter tree, the aspinothoracid arthrodires and the camuropiscid (Long, 1988) arthrodires plus Incisoscutum and 

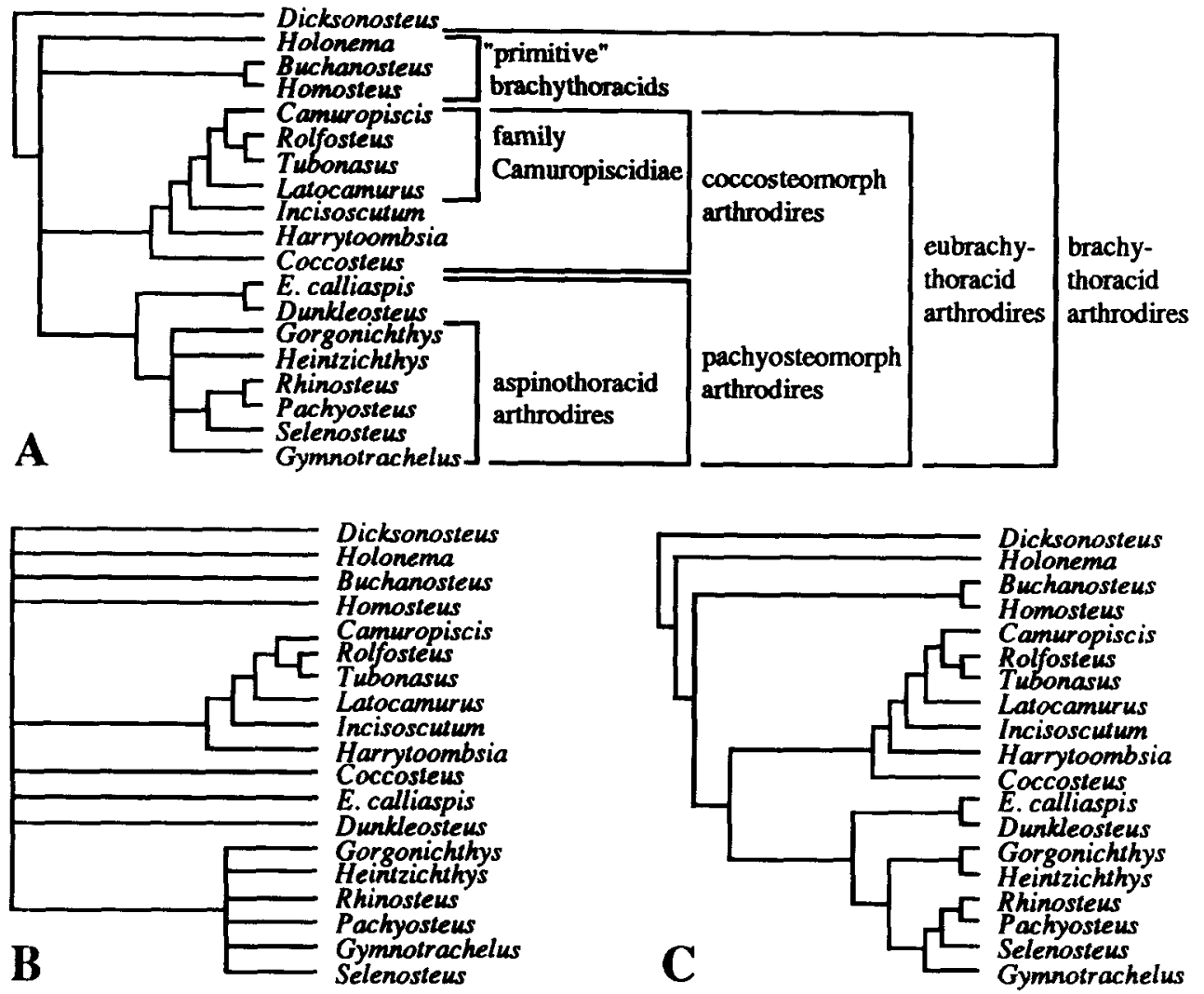

Figure 19. Cladograms showing various hypotheses of relationships as outlined in text. A, Strict consensus tree based on seven cladograms derived from PAUP. B, Strict consensus tree utilizing all possible combinations of the four outgroups (Dicksonosteus, Holonema, Buchanosteus and Homosteus). C, Fully resolved hypothesis of relationships.

Harrytoombsia remain monophyletic despite the choice of outgroup. Utilizing PAUP's default parameters ('hold trees' set as one) an additional six equally parsimonious trees are retrieved.

The analysis represented in Fig. 19A leaves the relationship of Holonema and the homosteids-buchanosteids unresolved. Five aiternative hypotheses of relationship are apparent from this analysis: (1) Holonema as the sister group to the homosteids-buchanosteids and eubrachythoracid arthrodires (Fig. 20A); (2) homosteids-buchanosteids as the sister group to Holonema and eubrachythoracid arthrodires (Fig. 20B); (3) homosteids-buchanosteids as the sister group to pachyosteomorph arthrodires (Fig. 20C); (4) homosteids-buchanosteids as the sister group to Holonema and coccosteomorph arthrodires (Fig. 20D); and (5) Holonema as the sister group to homosteids-buchanosteids and coccosteomorph arthrodires (Fig. 20E). Figure $20 \mathrm{~F}-\mathrm{H}$ represents equally parsimonious resolutions to the additional unresolved portions of Fig. 19A within the aspinothoracid arthrodires. These cladograms are taken from the seven trees used to generate Fig. 19A and are consistent with the six additional equally parsimonious trees. A fully resolved hypothesis of relationships is presented in Fig. 19C. The systematic discussion that follows is based on Fig. 19A, C. 
A

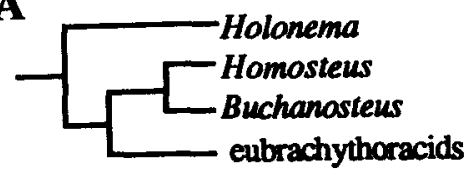

C

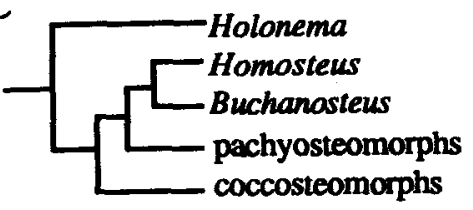

$\mathbf{E}$

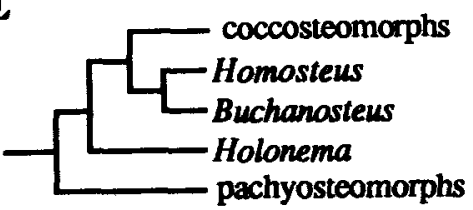

G

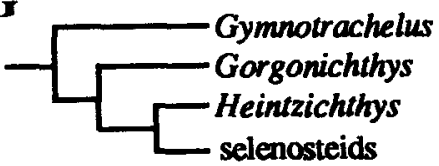

B

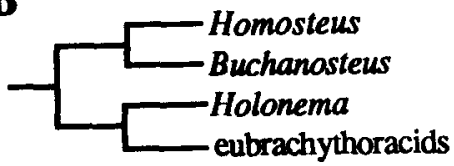

D

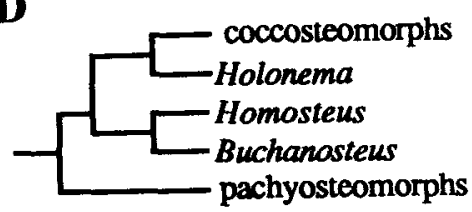

$\mathbf{F}$

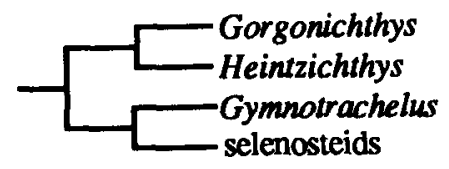

H

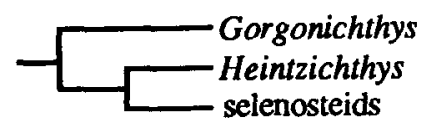

Figure 20. Equally parsimonious resolutions to unresolved portions of Fig. 19A. Cladograms represent portions of seven trees derived from PAUP analysis.

\section{Brachythoracid arthrodires}

The inclusion of Holonema within the brachythoracid arthrodires was proposed by Miles (1973), Miles \& Dennis, (1979), Goujet (1984), Lelièvre (1984a, b) and Gardiner \& Miles (1990); however, Denison (1978) and Young (1981) regarded Holonema as a phlyctaeniid arthrodire. Lelièvre argued for a sister-group relationship between holonematids and homosteids-buchanosteids ( = 'primitive' Brachythoraci-Lelièvre, 1984a, b, 1988). This relationship was supported solely by the presence of a postsuborbital sensory line groove on the suborbital plate and was evaluated in the absence of any outgroup analysis. The relationship of Holonema, as presented in this paper, is in conflict with both a phlyctaeniid and a 'primitive' brachythoracid assignment. Lelièvre (personal communication) recently suggested that Holonema represents the sister group to the remaining 'primitive' brachythoracids-eubrachythoracids. The homosteidsbuchanosteids and eubrachythoracid arthrodires are characterized by (1) the development of a lateral consolidated part of the internal surface of the head shield with the presence of an inframarginal crista (character 2); (2) a lateral displacement of the dermal cranio-thoracic articulation (Goujet, 1984: 246); (3) the reduction of the submarginal plate (character 60); (4) the development of a posterior process on the anterior superognathal (character 70); and (5) the loss of a sensory groove for the main lateral line on the posterior dorsolateral plate (character 79, reestablished in the eubrachythoracid arthrodires). The 
monophyly of the homosteids-buchanosteids is supported by characters 29,31 and 82.

\section{Eubrachythoracid arthrodires}

The diagnosis of eubrachythoracid arthrodires has been debated by Dennis \& Miles (1979a, b, 1980), Denison (1978), Young (1981) and Gardiner \& Miles (1990). This debate centres on a number of anatomical arguments and on the definition of various character states. A variety of characters has been proposed as diagnostic for the eubrachythoracid arthrodires. These include: (1) a trilobate central plate (character 19b of Young, 1981); (2) an inferognathal with coossified blade and occlusal regions (character 14 of Miles \& Dennis, 1979); (3) a lateral consolidated region on the internal surface of the head shield (character 15 of Miles \& Dennis, 1979); (4) a small submarginal plate closely associated with the cheek region (character 16 of Miles \& Dennis, 1979); (5) a supraorbital vault (character 17 of Miles \& Dennis, 1979); (6) a suborbital plate with a dermal suborbital lamina (character 18 of Miles \& Dennis, 1979); (7) internal laminae on the suborbital plate (character 21 of Miles \& Dennis, 1979); (8) a carinal process on the internal surface of the median dorsal plate (character 19 of Miles \& Dennis, 1979); (9) a preorbital plate with a dermal preorbital lamina (character 20 of Miles \& Dennis, 1979); (10) separate autopalatine and quadrate ossifications of the palatoquadrate (character 22 of Miles \& Dennis, 1979; Young, 1981); and (11) the presence of posterior processes on the superognathals (character 23 of Miles \& Dennis, 1979). A number of these putative synapomorphies are dependent upon a concise definition. The purpose of this discussion on proposed synapomorphies for the eubrachythoracid arthrodires is not to reject these characters, but to further point out the need for clarification.

Trilobate centrals are difficult to evaluate. The coccosteid-type of trilobate central possesses an embayment by both the preorbital and paranuchal plates. In addition, there is a posterior expansion of the central plate between the nuchal and paranuchal plates. It is important to differentiate variable development of the three lobes within the central plate. Miles \& Dennis (1979) evaluated the utility of this character in their discussion of Denison's (1975) description of the Coccosteina.

In the present study, the trilobate central is considered to be a composite of several features and is subdivided into a number of discrete characters (e.g. characters 13,14 and 21). The subdivision of this character provides greater information; for example, the presence of a preorbital embayment characterizes the coccosteomorph arthrodires (Fig. 19A).

Use of a co-ossified blade and occlusal region as a synapomorphy for eubrachythoracid arthrodires implies that 'primitive' brachythoracid, phlyctaeniid and actinolepid arthrodires either lack an ossified blade or that the two regions are present, but are independently ossified. Two questions arise in analysing this character: (1) the presence of a single ossification or co-ossified components in the inferognathal and (2) the phylogenetic level where an inferognathal blade first appears.

Orvig (1980) argued for the presence of two ossification centres within the inferognathal, one forming the non-biting region or blade and one forming the biting or 'functional' region. Heintz (1932), Miles \& Westoll (1968) and Miles 
(1969) presented arguments for the presence of a single ossification. It appears that the inferognathal is a single ossification with the development of a blade portion appearing early among brachythoracid arthrodires. A single ossification is clearly seen in Selenosteus (Orvig, 1980: figs 52-54) with the ossification centre located below the anterior cusp. The anterior location of ossification often makes it difficult in many forms to visualize the continuity between the occlusal portion and the blade.

The definition of a blade and the phylogenetic level of its occurrence is unclear. Lelièvre (1984b) noted the presence of a posterior non-masticatory region in Antineosteus and in Goodradigbeeon (see also White, 1978). Denison (1958: fig. 101D, F) figured two actinolepid inferognathals possessing a posterior nonbiting region. As further noted by Lelièvre (1984b) the posterior regions in these forms are characterized by a deep ventral or ventrolateral groove bounded laterally and medially by dermal laminae. Eubrachythoracid arthrodires and Homosteus may be characterized by the loss of the lateral lamina and the development of the lamina medial to Meckel's cartilage with an inferognathal blade representing an enhancement of the medial lamina. In Homosteus the presence of a laterally placed shallow ridge on the inferognathal (h, Heintz, 1934: fig. 27) may mark the boundary of Meckel's cartilage. Evaluation of the appearance of this character is difficult since inferognathals are unknown in several of the 'primitive' brachythoracids (Buchanosteus, Errolosteus, Taemasosteus, Arenipiscis and Tityosteus; Lelièvre 1988).

Development of a lateral consolidated arch on the internal surface of the head shield is seen in several 'primitive' brachythoracids (Homosteus, Heintz, 1934: fig. 2; Antineosteus, Lelièvre, 1984b: fig. 3), which differ from eubrachythoracid arthrodires only in the degree of development.

The submarginal plate as characterized by Miles \& Dennis 1979) also occurs in Homosteus (Heintz, 1934: figs. 24, 25). A small submarginal plate with overlap areas for the suborbital and marginal plates is found in Antineosteus (Lelièvre, 1984b; Fig. 12). This character appears to diagnose a homosteideubrachythoracid grouping (Fig. 19A, includes the 'primitive' brachythoracids of Lelièvre, 1988, with the exception of Holonema).

A supraorbital vault is bounded typically by the lateral consolidated arch in the orbital region. Anteriorly, this boundary is part of the internal thickening of the preorbital dermal lamina. A posterior supraorbital crista (= postorbital crista [cr.po] of Young, 1979) extends laterally from the lateral consolidated arch and forms the posterior boundary of the supraorbital vault. In Dunkleosteus, the neurocranial process extends medially from the posterior supraorbital crista. A triangular depression is often associated with this posterior boundary (e.g. Eastmanosteus calliaspis, tri, Dennis-Bryan, 1987). Miles \& Dennis (1979) correlated the development of a supraorbital vault with large laterally facing orbits. Homosteus has a very small supraorbital vault that lacks a posterior supraorbital crista (Heintz, 1934; Stensio, 1963: fig. 113D). In Antineosteus, the supraorbital vault is confined to the postorbital plate and is bounded by a low ridge (Lelièvre, 1984b: fig. 3). The medial boundary of the Antineosteus vault is not continuous with the lateral consolidated arch. Buchanosteus possesses both a supraorbital vault and a posterior supraorbital crista (Young, 1979: fig. 2). In the evaluation of the brachythoracid condition it is clear that a supraorbital vault is present but varies from the derived eubrachythoracid condition in the 
level of development of the vault. At the eubrachythoracid level and within Buchanosteus, the vault is intimately associated with the lateral consolidated arch and possesses a posterior supraorbital crista.

Antineosteus lacks a suborbital dermal lamina; however, it is present in Homosteus (Heintz, 1934: fig. 23) and in 'Parabuchanosteus' (White \& Toombs, 1972: figs 14, 15). Although the suborbital of Homosteus does not participate in the border of the orbit, it is clearly associated with the autopalatine. The internal pattern of cristae is similar to that seen in typical eubrachythoracid arthrodires. A subautopalatine crista, autopalatine depression, postocular crista $(\mathbf{R} 1)$ and posteroventral crista (R4) are present. The absence of a suborbital crista can be explained by the dorsomedian shift of the orbits.

Internal laminae on the suborbital plate have been interpreted in a number of ways and some confusion exists as noted above in the description of the suborbital plate for Heintzichthys gouldii. Only Eastmanosteus and Dunkleosteus have a contact face for the posterior superognathal on the linguiform process. This may represent either a synapomorphy for these two forms or a synapomorphy appearing at the eastmanosteid level (the group containing Eastmanosteus and Dunkleosteus being paraphyletic) and lost within the aspinothoracid arthrodires.

A carinal process on the internal surface of the median dorsal plate with a concave posterior face occurs in Buchanosteus (Young, 1979) and 'Parabuchanosteus' (White \& Toombs, 1972: fig. 17). Young (1979) used this character to diagnose brachythoracids (excluding Holonema).

The dermal preorbital lamina of the preorbital plate forms the anterodorsal border of the orbit when present. Internally, the lamina is thickened and forms the anterior boundary for the supraorbital vault. Medially, this internal thickening often possesses a depression for the preorbital process of the neurocranium and a depression lateral to the rhinocapsular region of the neurocranium. The preorbital plate in Antineosteus does not form part of the orbit border and lacks an internal thickening and distinguishable depressions. In contrast, Buchanosteus and Homosteus have internally thickened preorbital plate laminae. Each of these forms possesses a depression for the preorbital process of the neurocranium that is associated with the internal thickening. The depression lateral to the rhinocapsular region is present in Homosteus, but is lacking in Buchanosteus where the rhinocapsular region is anteriorly displaced.

Young (1979: fig. 16A, gr.mp) noted that Buchanosteus had a ventral groove on the autopalatine that he interpreted as the contact face for the posterior process of the posterior superognathal. The presence of a ventral groove in Buchanosteus suggests that the posterior process of the posterior superognathal is possibly plesiomorphic at the eubrachythoracid level. The posterior superognathals remain unknown.

In the present study, the following characters are considered diagnostic of eubrachythoracids (Fig. 19A, C): (1) separate autopalatine and quadrate ossifications within the palatoquadrate (character 57 ); (2) development of a continuous thickening across the posterior margin of the head shield (character 12); and (3) a supraorbital vault developed as part of the lateral consolidated arch and posteriorly bounded by the posterior supraorbital crista (a subjectively defined character not utilized in the current PAUP analysis).

Two subgroups of eubrachythoracid arthrodires are presented in Fig. 19A, C: coccosteomorph arthrodires and pachyosteomorph arthrodires. The first group 
includes the camuropiscids, Incisoscutum, Harrytoombsia and Coccosteus, while the second group includes the dinichthyid and aspinothoracid arthrodires. The relationships of a number of basal eubrachythoracid arthrodires (Coccosteus, Eastmanosteus calliaspis and Dunkleosteus) remain ambiguous and are dependent on the choice of outgroups (Fig. 19B). The cladogram in Fig. 19A is further supported by Gardiner \& Miles (1990) in their evaluation of a number of North American and Australian coccosteomorph taxa. Further analysis is needed in light of additional morphological evidence and additional taxa.

Dinichthys hertzeri, Eastmanosteus pustulosus and Eastmanosteus magnificus (Dinichthys magnificus, Hussakof \& Bryant, 1918) have been excluded from this analysis and represent forms requiring additional study. North American Eastmanosteus species share a number of primitive coccosteomorph-pachyosteomorph characteristics; however, they have been included traditionally in the family Dinichthyidae (Obruchev, 1964; Schultze, 1973; Denison, 1978). The holotype for Eastmanosteus pustulosus is a left, poorly preserved anterior dorsolateral plate (MCZ 1381). The preservation of the type specimen suggests that Eastmanosteus pustulosus may be a nomen dubium. Boylan (1973) attempted a reanalysis of the material assigned to Eastmanosteus pustulosus, but it is not clear whether the genus or the species represents a paraphyletic grouping based on shared primitive features. Fundamental to the phylogenetic analysis of these forms is the reanalysis of Dinichthys as suggested by Schultze (1973).

\section{Coccosteomorph arthrodires}

Miles (1969) suggested that a coccosteomorph level of organization includes those brachythoracid arthrodires which retain a closed pectoral fenestra. The order Coccosteomorphi, as originally described by Stensio (1944) is paraphyletic. A restricted use of the term coccosteomorph is commonly applied to the monophyletic group containing Coccosteus (equivalent to Denison's order Coccosteoidea, 1984). A potential relationship between Coccosteus and the pachyosteomorph arthrodires is consistent with a number of interpretations of the interrelationships among arthrodires (Boylan, 1973; Miles, 1969; Miles \& Dennis, 1979; Dennis \& Miles, 1979a, b). Boylan (1973) noted that Coccosteus, Eastmanosteus and Dunkleosteus were related; however, he removed the latter two taxa from the pachyosteomorph arthrodires and assigned them to the coccosteomorph arthrodires. A number of authors supported the derivation of Dunkleosteus from Coccosteus or from a Coccosteus level of organization. These interpretations are consistent with a sister-group relationship between Coccosteus and remaining pachyosteomorph arthrodires; however, the present analysis suggests that the coccosteomorph arthrodires are monophyletic. The coccosteomorph arthrodires (Fig. 19A) are characterized by (1) the preorbital plate embayment of the central plate (character 13, independently derived in Eastmanosteus calliaspis); (2) a reduction in the medial contact between the preorbital plates (character 19; however, this character remains ambiguous since taxa adjacent to the coccosteomorph arthrodires lack a medial contact); (3) a spinous posterior border on the median dorsal plate (character 37 ); (4) a posterior lateral plate lamina (character 44); (5) a pronounced posterior ventrolateral plate lamina (character 51); and (6) a median hypophysial vein foramen on the parasphenoid (character 73). 
Coccosteus is the sister group to the remaining coccosteomorph arthrodires (Fig. 19G). Characters 23 (marginal and central plates in contact) and 39 (contact between the anteroventral wing of the anterior lateral plate and the interolateral plate) diagnose the clade (Harrytoombsia (Incisoscutum, camuropiscids)). Rolfosteus and Tubonasus share the unique development of a ventrally enclosed tubular rostrum. Tubonasus retains plesiomorphic features of the occlusal portion of the inferognathal with Rolfosteus possessing durophagus dentition.

\section{Pachyosteomorph arthrodires}

The pachyosteomorph arthrodires include the dinichthyid and aspinothoracid arthrodires. This group is characterized by (1) the loss of the paranuchal embayment of the central plates (character 14); (2) a reduction of the contact between the nuchal and central plates (character 21 ); (3) the formation of a lateral contact between the suborbital and preorbital plates (character 54); and (4) the loss of the groove for the ventral portion of the main lateral line on the anterior dorsolateral plate (lc.vl, character 77). Character 14, a synapomorphy for the pachyosteomorph arthrodires, is dependent upon the monophyly of Eastmanosteus calliaspis and Dunkleosteus which are united by (1) the position of the posterior border of the pineal plate posterior to the orbits (character 9); (2) the insertion of the posterior lateral plate into a fossa within the posterior dorsolateral plate (character 42); (3) the presence of a contact face for the posterior superognathal on the linguiform process of the suborbital plate (character 56); (4) the presence of a groove for the main lateral line (lc, Miles, 1971: fig. 108) on the posterior dorsolateral plate (a synapomorphy if this groove is interpreted as an extension of the main lateral line and not the dorsal branch of the lateral line (ld, Miles, 1971: fig. 108); considered as unknown in Dunkleosteus for this analysis); and (5) the presence of anterior and lateral cusps on the anterior superognathal (character 66).

\section{Family Dinichthyidae}

Dunkleosteus and Eastmanosteus are members of the family Dinichthyidae (Newberry, 1885). Denison (1978) placed Heintzichthys and Gorgonichthys within the family Dinichthyidae; however, this placement was not based on any clearly defined derived characters. Heintzichthys and Gorgonichthys share a number of characters with the aspinothoracid arthrodires. The validity of the family Dinichthyidae is not clear since Dinichthys hertzeri is poorly known and additional analysis of Eastmanosteus pustulosus is required.

\section{Aspinothoracid arthrodires}

The Aspinothoracidi, originally proposed by Stensio (1959) and later modified by Miles \& Dennis (1979), is retained and diagnosed by the following characters: (1) a reduction in the lateral consolidated part of the head shield (character 2);

(2) an anterior shift of the preorbital/postorbital/central plate junction to a 
position over the orbit (character 33 ); (3) the loss of the spinal plate (character 45); and (4) the closure of the angle between the postorbital and otic branches of the infraorbital sensory canal associated with an enlargement of the orbits (character 75).

Denison (1984) assumed that the loss of spinal plates was independently derived in a number of families (Heterosteidae, Brachydeiroidea, Rhachiosteidae, and in some Dinichthyidae). He argued (p. 410) that these losses precluded the use of this character in diagnosing relationships. Denison further argued that using the loss of spinal plates would place members of the family Dinichthyidae in different suborders; however, he did not demonstrate the monophyly of the Dinichthyidae. As noted above, there are no derived characters that unite Heintzichthys and Gorgonichthys with Eastmanosteus and Dunkleosteus which were included by Denison within the family Dinichthyidae.

Heintzichthys and Gorgonichthys share a specialization of the anterior superognathal (character 67) and a loss of adsymphysial denticles on the inferognathal (character 65). The anterior superognathals in these taxa possess both the development of a lateral face and a short shelf posterior to the lateral cusp. Analysis of additional dinichthyids and further revision of the North American aspinothoracid arthrodires may help to resolve the relationships within the basal aspinothoracids.

\section{Selenosteid arthrodires}

Dean's original description of the Selenosteidae (1901) included only North American taxa and was based solely on primitive characters. Lelièvre et al. (1987), attempted a cladistic analysis of the Selenosteidae and related outgroups. They concluded that the Selenosteidae was the sister group to the Brachydeiridae; however, there is only a single character that unites members within Selenosteidae. This character is the closed posterior angle between the postorbital and otic divisions of the infraorbital sensory canal (Character 75). A closed angle between the two divisions of the infraorbital canal is also found in Trematosteidae (Belosteus, Denison, 1978: fig. 73C; Cyrtosteus, .Denison, 1978: Fig. 73D), Leiosteidae (Erromenosteus, Denison, 1978: fig. 72B), Heintzichthys (Fig. 2) and Pholidosteidae (Pholidosteus, Denison, 1978: fig. 64A). The posteriorly directed postorbital division of the infraorbital canal is correlated with enlarged orbits. It is not clear whether this condition represents a plesiomorphic state or is independently derived in each of these groups. A similar condition is approached independently in large-eyed camuropiscids from the Gogo Formation, Australia. Assignment of taxa to the family Selenosteidae differs among authors (Dean, 1901; Obruchev, 1964; Denison, 1978; Lelièvre et al., 1987).

Selenosteus is the sister group to the European selenosteids (Pachyosteus and Rhinosteus, Fig. 19A, C) which share an enlarged orbit (character 28) with closure of the angle between the postorbital and otic branches of the infraorbital canal groove (character 75). Future analysis of Gymnotrachelus and Selenosteus spp. based on material from the Interstate 71 Paleontological Salvage Project and additional preparation of the type specimens of Selenosteus brevis (AMNH 7312) and Stenosteus glaber (AMNH 7313) are needed in order to revise the North American selenosteids. 


\section{CONCLUSION}

Cladistic analysis of 19 taxa using 85 characters suggests: (1) Holonema is neither a phlyctaeniid nor a 'primitive' brachythoracid. Analyses by Lelièvre (personal communication) and Gardiner \& Miles (1990) suggesting that Holonema is the sister group to the 'primitive' brachythoracids-eubrachythoracids are supported by the present analysis. (2) Homosteus and Buchanosteus are retained as members of the 'primitive' brachythoracids. (3) The Coccosteomorphi, as established by Stensio (1944), are paraphyletic. A restricted use of this term is supported by the present work and that of Gardiner \& Miles (1990), but some ambiguity remains as to the position of Coccosteus based on the choice of outgroups (Fig. 19B). (4) Heintzichthys and Gorgonichthys are more closely related to other aspinothoracid arthrodires than they are to remaining members of the family Dinichthyidae. (5) A re-evaluation of the family Dinichthyidae would be useful. This analysis must await the preparation of additional Dinichthys material and the reanalysis and further preparation of the Eastmanosteus pustulosus material described by Boylan (1973). (6) Finally, a re-evaluation would be useful for several aspinothoracid arthrodiran families (e.g. Selenosteidae, Bungartiidae, Titanichthyidae, Mylostomatidae, Trematosteidae, Leiosteidae, Leptosteidae and Brachydeiridae).

\section{ACKNOWLEDGEMENTS}

I wish to especially thank Dr. Michael Williams who provided encouragement and access to the Cleveland Museum of Natural History collections. After a large part of the collection was severely damaged while on loan, Dr. Michael Williams and Gary Jackson were responsible for restoration of the damaged materials. Without their efforts, much of this valuable materal would have been lost.

I want to thank Drs Daniel Goujet, Hervé Lelièvre, Kim Dennis-Bryan and Professor Brian Gardiner for their encouragement and early reviews of this manuscript. In addition, my appreciation is extended to Drs Peter Forey and Sally Young for their support and assistance while working with the collections at the Natural History Museum, London.

Financial support from The Scott Turner Awards in Earth Science, The University of Michigan and Sigma $\mathrm{Xi}$, The Scientific Research Society is gratefully acknowledged.

\section{REFERENCES}

BOYLAN, J. C., 1973. Eastmanosteus, a placoderm from the Devonian of North America. Unpublished Ph.D. thesis, Columbia University.

CLAYPOLE, E. W., 1893. The fossil fishes of Ohio. Report of the Ohio Geological Survey, 7(2): 602-619.

DEAN, B., 1896. On the vertebral column, fins and ventral armoring of Dinichthys. Transactions of the New York Academy of Sciences, 15: 157-163.

DEAN, B., 1901. III. Further notes on the relationships of the Arthrognathi. Memoirs of the New York Academy of Sciences, 2: 110-123.

DENISON, R. H., 1958. Early Devonian fishes from Utah. Part III. Arthrodira. Fieldiana. Geology, 11: $461-551$.

DENISON, R. H., 1975. Evolution and classification of Placoderm fishes. Breviora, 432: 1-24.

DENISON, R. H., 1978. Handbook of Paleoichthyology. 2. Placodermi. Stuttgart: Gustav Fischer Verlag.

DENISON, R. H., 1984. Further consideration of the phylogeny and classification of the Order Arthrodira (Pisces: Placodermi). Journal of Vertebrate Paleontology, 4(3): 396-412.

DENNIS-BRYAN, K. D., 1987. A new species of eastmanosteid arthrodire (Pisces: Placodermi) from Gogo, Western Australia. Zoological Joumal of the Linnean Society, 90: 1-64. 
DENNIS, K. D. \& MILES, R.S., 1979a. A second eubrachythoracid arthrodire from Gogo, Western Australia. Zoological Joumal of the Linnean Society, 67: 1-29.

DENNIS, K. D. \& MILES, R. S., 1979b. Eubrachythoracid arthrodires with tubular rostral plates from Gogo, Western Australia. Zoological Joumal of the Linnean Society, 67: 297-328.

DENNIS, K. D. \& MILES. R. S., 1980. New durophagus arthrodires from Gogo, Western Australia. Zoological Fournal of the Linnean Society, 69: 43-85.

DENNIS, K. D. \& MILES, R.S., 1981. A pachyosteomorph arthrodire from Gogo, Western Australia. Zoological Journal of the Linnean Society, 73: 213-258.

DENNIS, K. D. \& MILES, R. S., 1982. A eubrachythoracid arthrodire with a snub-nose from Gogo, Western Australia. Zoological Journal of the Linnean Society, 75: 153-166.

DUNKLE, D. H. \& BUNGART, P. A., 1946. The antero-supragnathal of Gorgonichthys. American Museum Novitates, 1316: $1-10$.

GARDINER, G. \& MILES, R. S., 1990. A new genus of eubrachythoracid arthrodire from Gogo, Western Australia. Zoological Joumal of the Linnean Society, 90: 159-204.

GOUJET, D., 1984. Les Poissons Placodermes du Spitsberg. Arthrodires Dolichothoraci de la Formation de Wood Bay (Dévonien Inférieur). Paris: Cahiers de Paléontologie.

HEINTZ, A., 1931. A new reconstruction of Stenognathus gouldii. Annals and Magazine of Natural History, 10(8): 242-249.

HEINTZ, A., 1932. The structure of Dinichthys: a contribution to our knowledge of the Arthrodira. Bashford Dean Memorial Volume-Archaic Fishes, 4: 115-224.

HEINTZ, A., 1934. Revision of the Estonian Arthrodira. Part 1, Family Homosteidae. Arkhiv für die Naturkunde Estlands, Tartu, 10(4): 1-114.

HLAVIN, W.J., 1976. Biostratigraphy of the Late Devonian black shales on the cratonal margin of the Appalachian geosyncline. Unpublished Ph.D. thesis, Boston University.

HUSSAKOF, L., 1911. Notes on some Upper Devonian Arthrodira from Ohio, U.S.A., in the British Museum (Natural History). Geology Magazine, 5(8): 123-128.

HUSSAKOF, L. \& BRYANT, W., 1918. Catalog of fossil fishes in the museum of the Buffalo Society of Natural Science. Buffalo Society of Natural Science Bulletin, 12: 1-346.

LEHMAN, J. P., 1956. Les arthrodires du Dévonien supérieur du Tafilalet (sud marocain). Notes et Mémoires. Service Géologique du Maroc, 129: 1-170.

LELIEVRE, H., 1984a. Atlantidosteus hollardi n. g., n. sp., nouveau Brachythoraci (Vertébrés, Placodermes) du Dévonien inférieur du Maroc présaharien. Bulletin du Muséum national deHistoire naturelle, Paris, 4: 197-208.

LELIEVRE, H., 1984b. Antineosteus lehmani n. g., n. sp., nouveau Brachythoraci du Dévonien inférieur du Maroc présaharien. Annales de Paléontologie, 70: 115-158.

LELIEVRE, H., 1988. Nouveau matériel d'Antineosteus lehmani Lelièvre, 1984 (Placoderme, Brachythoraci) et d'Acanthodiens du Dévonien inférieur (Emsien) d'Algérie. Bulletin du Muséum national d'Histoire naturelle, 4: 287-302.

LELIEVRE, H., JANVIER, P, \& GOUJET, D., 1981. Les vertébrés dévoniens de l'Iran Central IV: arthrodires et ptyctodontes. Geobios, 14(6): 677-709.

LELIEVRE, H., FEIST, R., GOUJET, D. \& BLIECK, A., 1987. Les vertébrés dévoniens de la Montagne Noire (sud de la France) et leur apport à la phylogénie des pachyostéomorphes (Placodermes' Arthrodires). Palaeovertebrata, 17(1): 1-26.

LONG, J., 1988. A new camuropiscid arthrodire (Pisces: Placodermi) from Gogo, Western Australia. Zoological Journal of the Limean Society, 94: 233-258.

MILES, R.S., 1969. Features of placoderm diversification and the evolution of the Arthrodire feeding mechanism. Transactions of the Royal Society of Edinburgh, 68: 123-170.

MILES, R. S., 1971. The Holonematidae (placoderm fishes), a review based on new specimens of Holonema from the Upper Devonian of Western Australia. Philosophical Transactions of the Royal Society of London, 263: 101-234.

MILES, R.S., 1973. An actinolepid arthrodire from the lower Devonian Peel Sound formation, Prince of Wales Island. Palacontographica, 143A: 109-118.

MILES, R.S. \& DENNIS, K. D., 1979. A primitive eubrachythoracid arthrodire from Gogo, Western Australia. Zoological Joumal of the Linnean Society, 65: 31-62.

MILES, R. S. \& WESTOLL, T. S., 1968. The placoderm fish Coccosteus cuspidatus Miller ex Agassiz from the Middle Old Red Sandstone of Scotland Part I. Descriptive morphology. Transactions of the Royal Society of Edinburgh, 67: 373-476.

NEWBERRY, J. S., 1885. Descriptions of some gigantic placoderm fishes recently discovered in the Devonian of Ohio. Transactions of the New York Academy of Sciences, 5: 25-28.

NEWBERRY, J.S., 1889. The Paleozoic Fishes of North America. Monographs of the U.S. Geological Survey, 16: $1-228$.

NEWBERRY, J. S., 1897. New species and a new genus of American Palcozoic fishes. Transactions of the New rork Academy of Sciences, 16: 282-304.

OBRUCHEV, D. V., 1964. Class Placodermi. Fundamentals of Paleontology, XI. Moscow. [In Russian. Translated by the Israel Program for Scientific Translations in 1967]. 
ØRVIG, T., 1980. Histological studies of ostracoderms, placoderms and fossil elasmobranchs. 3. Structure and growth of the gnathalia of certain arthrodires. Zoologica Scripta, 9:141-159.

PATTERSON, C., 1982. Morphological characters and homology. In K. A. Joysey \& A. E. Friday (Eds), Problems of Phylogenetic Reconstruction: 21-74. New York \& London: Academic Press.

SCHULTZE, H., 1973. Large Upper Devonian arthrodires from Iran. Fieldiana (Geology), 23: 53-78.

STENSIO, E. A., 1944. Contributions to the knowledge of the vertebrate fauna of the Silurian and Devonian of Podolia. II. Notes on two Arthrodires from the Downtonian of Podolia. Arkiv für Zoologi, 35: 1-83.

STENSIO, E. A., 1959. On the pectoral fin and shoulder girdle of the arthrodires. Kungliga Svenska Vetenskapsakademiens Handlingar, 8: 1-229.

STENSIO, E. A., 1963. Anatomical studies on the arthrodiran head. Part I. Preface, geological and geographical distribution, the organization of the head in the Dolichothoraci, Coccosteomorphi, and Pachyosteomorphi. Taxonomic appendix. Kungliga Svenska Vetenskapsakademiens Handlingar, 9: 1-419.

SWOFFORD, D. L., 1989. Phylogenetic analysis using parsimony (PAUP). Version 3.0. Champaign, Illinois, Illinois Natural History Survey.

VEZINA, D., 1988. Plourdosteus canadensis (Woodward 1892), un arthrodire du Frasnien inférieur du Canada: contribution à l'étude morphologique phylogénétique des Plourdosteidae (Vertebrata, Placodermi) du Dévonien moyen et superieur. Unpublished Ph.D. thesis, University of Paris VII.

WHITE, E. I. 1978. The larger arthrodiran fishes from the area of the Burrinjuck Dam, N.S.W. Transactions of the Zoological Society of London, 34: 149-262.

WHITE, E. I. \& TOOMBS, H. A., 1972. The buchanosteid arthrodires of Australia. Bulletin of the British Museum (Natural History), Geology, 22: 377-419.

WHITLEY, G. P., 1933. New names for fossil fishes. Copeia, 3: 146.

WILLIAMS, M., 1990. Feeding behavior in Gleveland Shale fishes. In A. J. Boucot (Ed.), Evolutionary Paleobiology of Behavior and Coevolution: 273-287. Elsevier Science Publishers.

YOUNG, G. C., 1979. New information on the structure and relationships of Buchanosteus (Placodermi, Euarthrodira) from the early Devonian of New South Wales. Zoological Journal of the Linnean Society, 66: 309-352.

YOUNG, G. C., 1981. New Early Devonian brachythoracids (placoderm fishes) from the Taemas-Wee Jasper region of New South Wales. Alcheringa, 5: 245-271.

\section{ABBREVIATIONS USED IN TEXT AND FIGURES}

$\begin{array}{ll}\text { a.Au } & \text { depression for autopalatine } \\ \text { ADL } & \begin{array}{l}\text { anterior dorsolateral plate } \\ \text { anterior lateral plate }\end{array} \\ \text { AMV } & \text { anterior median ventral plate } \\ \text { art.cr } & \text { articular crest } \\ \text { ASG } & \text { anterior superognathal } \\ \text { a.th } & \text { anterior thickening } \\ \text { AVL } & \text { anterior ventral plate } \\ \text { av.w } & \text { anteroventral wing } \\ \text { C } & \text { central plate } \\ \text { cd.art } & \text { region of articular condyle } \\ \text { cf.AL } & \begin{array}{l}\text { contact face for anterior lateral } \\ \text { plate }\end{array} \\ \text { cf.AMV } & \begin{array}{l}\text { contact face for anterior median } \\ \text { ventral plate }\end{array} \\ \text { cf.P } & \text { contact face for pineal plate } \\ \text { cf.PSG } & \text { contact face for posterior } \\ \text { ch.eth } & \begin{array}{l}\text { superognathal } \\ \text { channel for ethmoid region of }\end{array} \\ \text { ch.pro.pr } & \begin{array}{l}\text { neurocranium } \\ \text { channel for dorsal aspect of } \\ \text { preorbital process of neurocranium } \\ \text { cribrosal region of neurocranium }\end{array} \\ \text { crib } & \text { inframarginal crista } \\ \text { cr.inf } & \text { postocular crista } \\ \text { cr.po } & \text { carinal process } \\ \text { cr.pr } & \text { posterior supraorbital crista } \\ \text { cr.pso } & \text { subautopalatine crista } \\ \text { cr.sau } & \text { supraethmoid crista } \\ \text { cr.seth } & \text { subocular crista } \\ \text { cr.so } & \text { central sensory canal } \\ \text { csc } & \end{array}$

\begin{tabular}{|c|c|}
\hline dp.m.cu & depression for cuccularis muscle \\
\hline gr & groove \\
\hline IG & inferognathal \\
\hline IL & interolateral plate \\
\hline $\begin{array}{l}\text { ioc.ot } \\
\text { ioc.sb }\end{array}$ & $\begin{array}{l}\text { otic branch of infraorbital canal } \\
\text { suborbital branch of infraorbital } \\
\text { canal }\end{array}$ \\
\hline $\mathbf{k}$ & knob \\
\hline kd & glenoid condyle \\
\hline laf & lateral articular fossa \\
\hline lc & main lateral line \\
\hline Im & thickened lower margin \\
\hline $\mathbf{M}$ & marginal plate \\
\hline m.sc & muscle scar \\
\hline Met & metapterygium \\
\hline MD & median dorsal plate \\
\hline m.sept & median septum \\
\hline n.th & nuchal thickening \\
\hline Nu & nuchal plate \\
\hline oa.ADL & $\begin{array}{l}\text { overlap area for anterior dorsal } \\
\text { lateral plate }\end{array}$ \\
\hline oa.AVL & $\begin{array}{l}\text { overlap area for anterior lateral } \\
\text { plate }\end{array}$ \\
\hline oa.AVL & $\begin{array}{l}\text { overlap area for anterior ventral } \\
\text { lateral plate }\end{array}$ \\
\hline oa.IL & overlap area for interolateral plate \\
\hline oa.MD & overlap area for median dorsal plate \\
\hline & $\begin{array}{l}\text { overlap area for posterior lateral } \\
\text { plate }\end{array}$ \\
\hline oa.PVL & overlap area for posterior ventral \\
\hline
\end{tabular}




$\begin{array}{ll}\begin{array}{l}\text { oa.SO } \\ \text { olf.tr }\end{array} & \begin{array}{l}\text { overlap area for suborbital plate } \\ \text { olfactory tract } \\ \text { pineal plate }\end{array} \\ \text { P } & \begin{array}{l}\text { occipital para-articular process } \\ \text { posterior dorsolateral plate } \\ \text { pap }\end{array} \\ \text { PDL } & \begin{array}{l}\text { pectoral embayment } \\ \text { posterolateral plate }\end{array} \\ \text { p.emb } & \text { posterolateral angle } \\ \text { PL } & \text { posterolateral process } \\ \text { pl.a } & \text { postmarginal plate } \\ \text { pl.pr } & \text { postmarginal canal } \\ \text { PM } & \text { posterior median ventral plate } \\ \text { pmc } & \text { paranuchal plate } \\ \text { PMV } & \text { median posterior process } \\ \text { PNu } & \text { posterior process } \\ \text { p.pr } & \text { prehypophysial region } \\ \text { p.pro } & \text { detent process } \\ \text { pre.reg } & \text { pr.det }\end{array}$

PrO

pr.sg

PSG

PSO

$\mathrm{PtO}$

pt.u

PVL

R

SM

SO

soc

sorc

suo.v

th.pbe

vl preorbital plate

subglenoid process

posterior superognathal

postsuborbital plate

postorbital plate

paired pits on visceral surface of nuchal plate

posterior ventrolateral plate rostral plate

submarginal plate

suborbital plate

supraorbital sensory canal groove supraoral sensory canal groove

supraorbital vault

prebranchial thickening

ventral lamina 


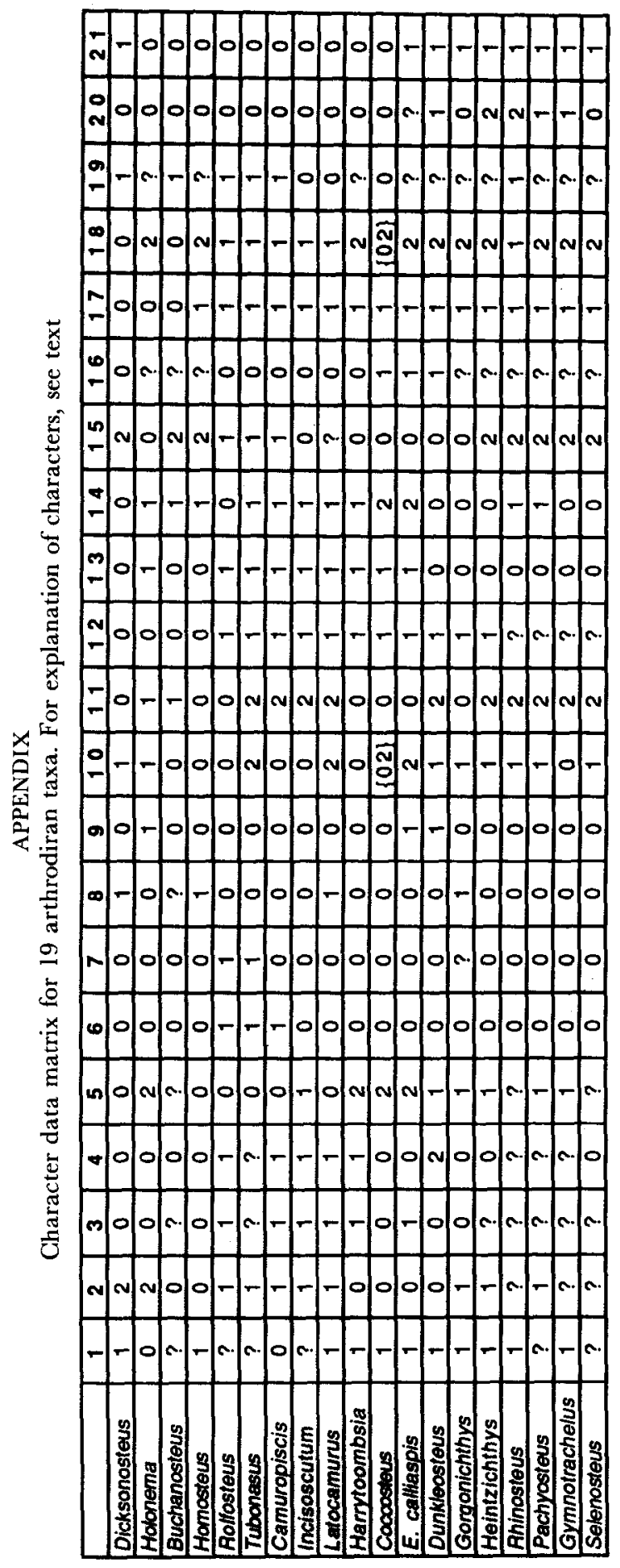

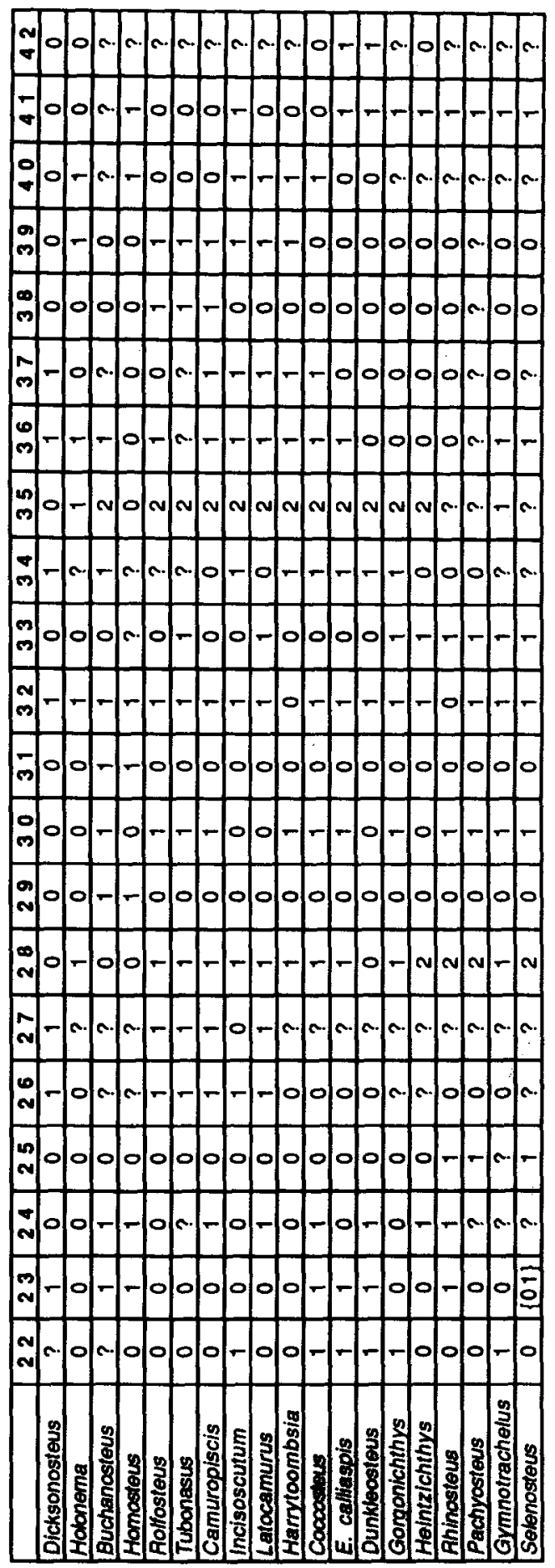




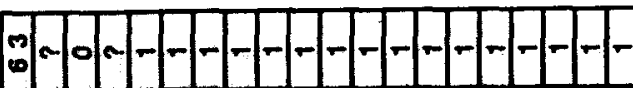

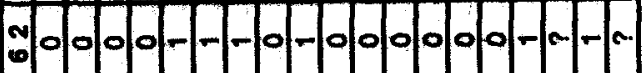

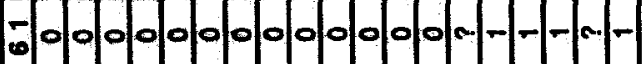

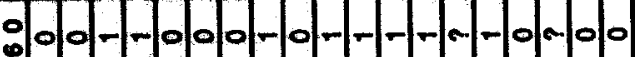

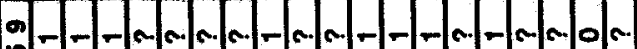

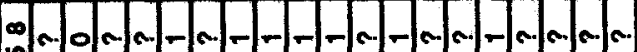

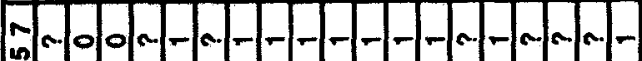

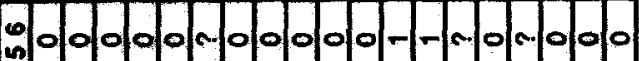

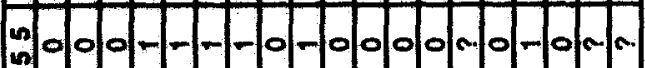

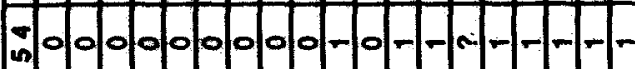

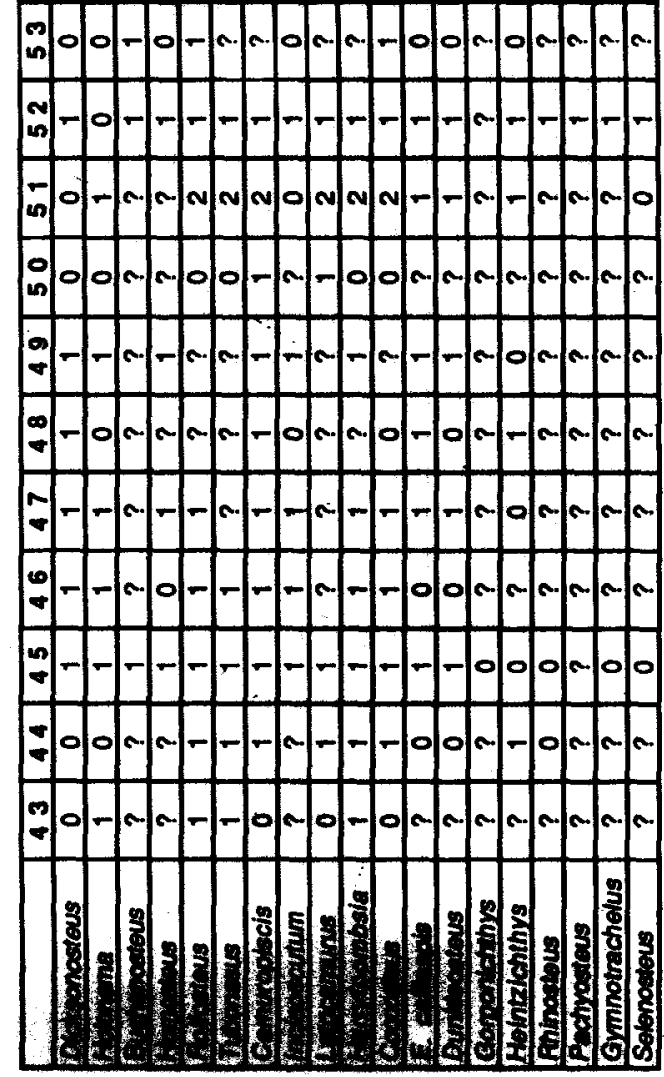

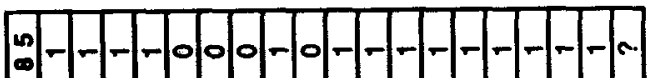

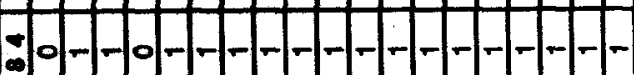

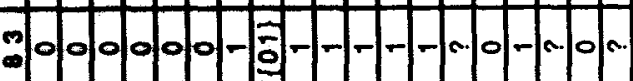
N D

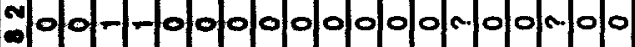

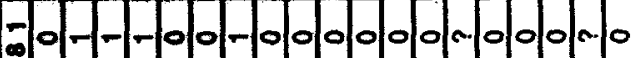

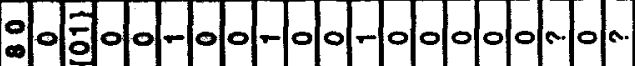

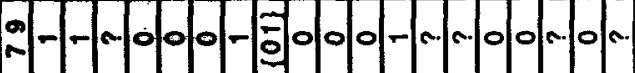

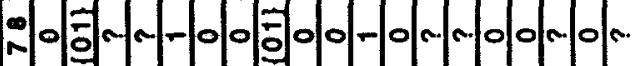

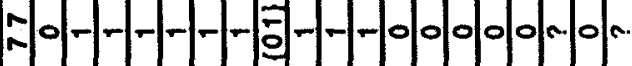

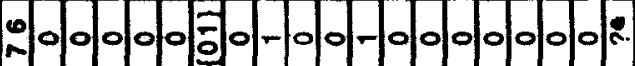

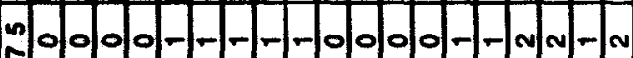

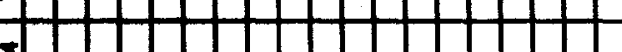

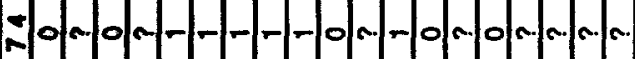

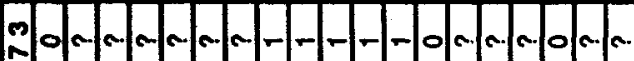
If 1 H

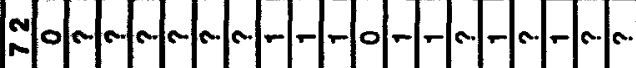

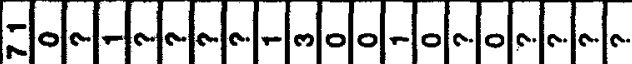

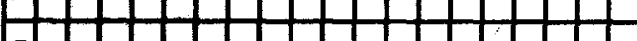

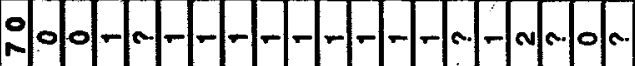

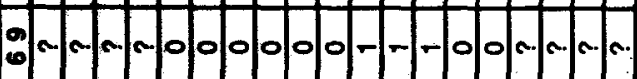

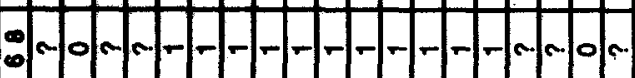
ma m

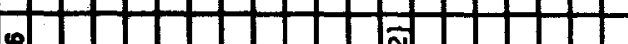
-

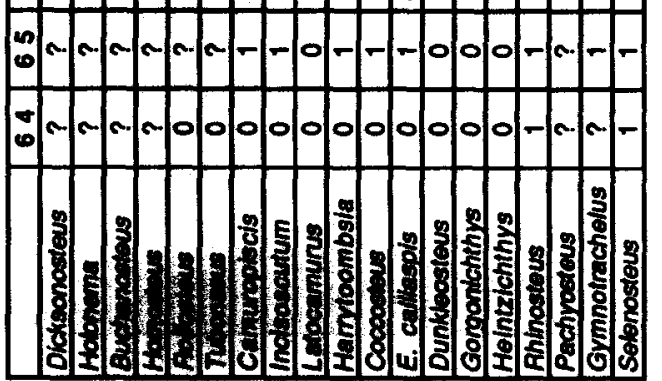

